\title{
Labor Market Policies and Outcomes: Cross Country Evidence for the EU-27
}

\author{
Riccardo Rovelli ${ }^{1}$ \\ Università di Bologna, DARRT and IZA. riccardo.rovelli@unibo.it
}

Randolph Bruno

Università di Bologna, DARRT and IZA. randolph.bruno@unibo.it

4 November 2007

\begin{abstract}
We conduct a comparative analysis of Labor Market Policies and outcomes for the EU member states, for the period 2000-2005.

We document the main differences in Labor Market Policies across EU members, including new members states after 2004. We focus on indicators of policy generosity (expenditures relative to GDP) and relate these and other policy indicators to indicators of labor market outcomes and performance.

Our results show that, on a cross-country basis, higher rates of employment are in general associated with: (i) higher expenditures on labor market policies, especially on active policies; (ii) a lower degree of rigidity in labor market institutions and in product market regulation.
\end{abstract}

JEL Classification: J08, J38, J68.

Keywords: Labor market policies. Labor market outcomes.

European social models.

1 Corresponding author. We thank Hartmut Lehmann and Anzelika Zaiceva for their comments. Marta Regalia assembled the data and produced all the graphs and figures. 


\section{Introduction}

The state of labor markets is at the center of many analyses and debates on the economies of the European Union. Indeed, "eurosclerosis" is the term coined in the Eighties to identify the slow growth, low employment and rigid labor markets in many "older" member states of the EU. On the positive side, the goal to increase labor market participation is at the center of the Lisbon strategy, which the Heads of State or Government of the EU adopted in March 2000. At the center of this strategy was an objective to increase the job market participation across all member states up to $70 \%$ by 2010 - a goal that all EU-15 members, but those who had already achieved it in 2000, are likely to miss. Nevertheless, the functioning of labor markets is at the center of both the economic and the social pillar of the Lisbon strategy, and also of its reappraisal in 2005.

Not only are labor markets central to economic performance, they also lie at the heart of the social models which so peculiarly characterize many EU members. In a recent Eurobarometer Survey on "European social reality" (2007), a majority (51\%) of European Union citizens declared their satisfaction with the quality of the social welfare system in their own country ${ }^{2}$. The report also notes that "over twofifths of European Union citizens feel that their welfare system could serve as a model for other countries (42\%). This belief is most widely held in Finland (79\%) and Denmark (78\%) and least widely so in Portugal (5\%), Latvia (6\%) and Greece (8\%). In Romania and Bulgaria this view is shared by respectively $7 \%$ and $2 \%$ of respondents. People's propensity to feel that their country's social welfare system could serve as a model for other countries is strongly related to whether they feel it provides enough coverage." (id., p.77).

Clearly, social policies matter to the EU citizens. However, shared values and common objectives do not necessarily imply EU competences or EU legislative action. In fact, in most cases subsidiarity implies that competences in the field of social and labor market policies should rest with member states. As the above quote from the Eurobarometer implies, many citizens are indeed happy with the diversity of social policies in Europe - what make some of them unhappy are the shortcomings of their national welfare systems.

2 The specific question asked to the EU-25 citizens was whether their welfare system "provides wide enough coverage" (Eurobarometer Survey, 2007, p.76) 
In this paper we characterize the main cross-country differences in labor market policies across EU member states, and relate various measures and policy indicators to indicators of labor market outcomes and performance. In doing so, we can take advantage of recently developed datasets, which include labor market and related indicators and variables, encompassing all or many of the current EU members. Some characteristics of these datasets, especially in the time domain, limit the range of the issues that can be explored. In particular, we shall limit ourselves to an analysis of how employment or unemployment measures are correlated across countries to indicators of labor and product market rigidities, and also to various measures of both active and passive labor market programs.

The paper is organized as follows. In Section 2 we synthesize the variety of labor market institutions and policies within the EU, in reference to all 27 member states. Section 3 motivates the basic framework and hypotheses underlying the econometric analysis. This analysis, relating policy and performance indicators, is then documented in Section 4. The interpretation of the results, together with some robustness and specification checks, are discussed in Section 5. Section 6 concludes. A short Appendix describes the data.

\section{One market for goods, many markets for labor. Up to what point? ${ }^{3}$}

In this section we propose to examine some diversities of economic performance that emerge, within the Internal Market (IM), among the different member states. In particular, we will tentatively correlate such diversities with the different models of labor market models and policies that have been adopted within each EU country. Also, we shall document to some extent how both policy inputs and economic performances have evolved in recent years.

We extend the comparison, as far as feasible, to the whole set of the current EU 27 members. In order to do this in a meaningful way, we focus only on the short period from 2000 to 2005 . This choice is motivated by two reasons. First, by the year 2000 the ten transition countries which have now entered into the EU had by most standards completed the period of transitional "confusion". Everywhere posttransition output had completed its U-shaped path; each country had been fully democratic for quite some time; and each was about to qualify as a full market

\footnotetext{
3 This section borrows extensively from Rovelli (2007).
} 
economy. Second, Eurostat has now assembled a rich data set of indicators, where all EU-27 members are adequately represented at least since $2000{ }^{4}$

Moving on to the analysis of these data, the questions we want to address are:

- Is it correct to group EU members within 4 social models, as it had been suggested, among others, by Boeri (2002) and Sapir (2004)?

- Do the groupings within each model stay constant across time?

- Do all the 27 members fit within these models, and precisely where?

- What defines countries to be member of one or another social model? Is it the adoption of certain policies ("policy inputs"), or the realization of certain achievements ("outcomes"), or both?

- What can we say about the economic performance of countries within each model? ${ }^{5}$

This section is divided in several parts. Section 2.1 describes the "four models" at the basis of the analysis. In section 2.2, these are re-appraised in reference to the member states of EU-27. Outcomes of social policies are examined in some more detail in section 2.3, and in section 2.4 they are related to different policy inputs.

\subsection{The Four models}

Box 1 recalls a well-known definition of the four models of social policy prevailing in the $\mathrm{EU}$ at the end of the $20^{\text {th }}$ century.

\footnotetext{
${ }^{4}$ Although the Eurostat data play the greater part in our dataset, in many cases we have complemented them with data from other sources. See the Data Appendix.

${ }^{5}$ In addition to these, there are other questions that we would like to address, but have postponed for the time being: Why do countries (choose to) belong to one social model or the other? Are switches between models feasible? Or instead, is it more likely to observe convergence? What causes the decision to switch, or to converge? Do we also see model (or policy) reversals? And what does cause them? In particular, is a decision about policy change related to the bad performance of the policy itself, or to its unfavorable economic performance? How are economic performances reflected in the policy choices of each member state, and in particular how are they mediated through the changing preferences of the electorate? These questions, however, will hopefully be addressed in some follow-up papers.
} 


\section{Box 1}

\section{The Four social policy models according to Boeri (2002)}

Boeri (2002), following Ferrera (1998) and Bertola et al. (2001) suggests that the EU15 members could be assigned to four different social policy models, covering four different geographical areas:

"There are, first of all, the Nordics (Denmark, Finland and Sweden, plus The Netherlands which is a hybrid between the Scandinavian and the Continental models and has recently moved Northwards) featuring the highest levels of social protection expenditures, and universal welfare provision based on the citizenship principle. Extensive fiscal intervention in labour markets, based on a variety of "active" policy instruments, substantial tax wedges, and relatively extensive employment in the public sector also belongs to this model while unions' presence in the workplace and involvement in the setting and administration of unemployment benefits generates compressed wage structures.

Next, we have the Anglo-Saxon countries (Ireland and the UK), which are closer to the Beveridgian tradition and feature relatively large social assistance of the last resort schemes. Cash transfers are primarily oriented to people in working-age. Activation measures are important as well as schemes conditioning access to benefits to regular employment. On the labour market side, this model is characterized by a mixture of weak unions, comparatively wide and increasing wage dispersion and relatively high incidence of low-pay employment, half-a-way between Europe and the US.

Continental European countries (Austria, Belgium, France, Germany, and Luxembourg), the third group, rely extensively on insurance-based, non-employment benefits and old-age pensions. Large invalidity benefit schemes are also present, which rely on contributions on employment income, along the Bismarckian tradition. While unions' membership rates have been falling quite dramatically in the last 20-25 years (Boeri, Brugiavini and Calmfors, 2001), a strong unions' influence has been to a large extent preserved by regulations artificially extending the coverage of collective bargaining much beyond unions' presence.

Finally, we have the Mediterranean countries (Greece, Italy, Spain and Portugal), concentrating their spending on old-age pensions and allowing for a high segmentation of entitlements and status. Their social welfare systems typically draw on employment protection and early retirement provisions to exempt segments of the working age population from participation in the labour market. Also in this case, strong unions' influence has been preserved by practices (e.g., jurisprudence) artificially extending the coverage of collective bargaining. As a result, wage structures are, at least in the formal sector, covered by collective bargaining and strongly compressed in these countries." 
Boeri also suggests that: "Three are the main tasks assigned to labour and social policies: i) reduce poverty and, more broadly, income inequalities, ii) protect against uninsurable labour market risk (and its interactions with longevity risk), and iii) increase the rewards from labour market participation."

Of these tasks, according to Boeri the third one is especially crucial to the macroeconomic performance of the EU, and also to the success of the Lisbon Strategy:

"The macroeconomic performance of Europe in the years to come, its ability to become "the most dynamic economy of the World" will very much depend also on its capacity to score better than the US also on the third criterion."

"... Increasing competition among systems in Europe has the potential to result in better outcomes in Europe in terms of the third criterion and is not incompatible with a persistently better record of Europe in terms of criteria i) and, possibly, ii)."

"However, competition among systems takes a long time to materialise. EU supranational authorities may play some role in speeding up this process only if they resist the temptation to impose a particular social model over the others and rely instead on the mobility of the European workforce as a driving force of political integration and social policy convergence."

But why do different countries choose different models of social policy? In his analysis, Boeri observes that "protection against uninsurable labour market risk is typically provided in two ways: (i) by imposing legal restrictions against firing - the so called employment protection legislation (EPL); (ii) by providing unemployment benefits in addition to those established by collective bargaining (UB). The differences between these two systems are clear: EPL protect those who already have a job, and do not impose any tax burden; UB can also be targeted to specific groups, but generally provide insurance to the population at large and are typically financed by a tax on those who work. Thus insiders, those with a stable and regular job, typically prefer EPL to UB".

Figure 1 effectively shows how EU countries, toward the end of the 1990s, where characterized by different positions along the EPL-UB tradeoff. In this picture, the four models emerge with sufficient distinction from each other.

[Figure 1 : Boeri 2002] ${ }^{6}$

[Figure 2 : Sapir 2004]

\footnotetext{
${ }^{6}$ All the figures are shown at the end of the paper.
} 
Following along similar lines of reasoning, Sapir (2004) evaluates the performance of the four models according to the third criterion, that is how they may stimulate labor market participation. He observes that the performance of the four models can be usefully compared "with a typology based on two criteria: efficiency and equity. A model will be considered efficient if it provides sufficient incentives to work and, therefore, if it generates relatively high employment rates. It will be deemed equitable if it keeps the risk of poverty relatively low." This comparison is depicted in Figure 2. The four models again appear neatly.

This leaves us with two open questions, which we take up in turn in the following two sub-sections:

(i) Is the diversity of labor market policies today still adequately described by the EPL-UB tradeoff?

(ii) Is there today a systematic link between the adoption of a policy stance in one country and the specific position which it assumes on the equity-efficiency tradeoff?

\subsection{Beyond the four models: a reappraisal for the EU-27}

Does a tradeoff still exist between the amount of (ex ante) protection (measured by the strictness of EPL) and the amount of (ex post) insurance (measured by the payment of UB)? And how does participation to other Labor Market Programmes (LMP) enter into the picture? In this section we shall argue that the EPL-UB tradeoff no longer provides a useful way to summarize the different attitudes of EU members towards labor market policies. Instead, it seems more appropriate to distinguish between countries in terms of the overall policy "generosity".

Three things have changed, since the beginning of this decade: some countries have had time to improve their old, or to adopt new policies; new members have joined the EU; and we have more and better statistics. ${ }^{7}$ As a starting point to our study, let us look at the data assembled in Table $1 .^{8}$

\footnotetext{
${ }^{7}$ See the Data Appendix at the end of the paper.

${ }^{8}$ Eurostat adopts the following, 9-dimensional classification of LMP:

1. Expenditure in labour market services.

2. Expenditure in training.

3. Expenditure in job rotation and job sharing.

4. Expenditure in employment incentives.

5. Expenditure in integration of the disabled.
} 
[Table 1 ]

The first six columns display expenditures in LMP as a ratio to GDP for all available EU countries, as well as their respective rank. We distinguish between expenditures on active or passive programmes (the latter include UB, redundancy and early retirement). As a reference point, the average expenditure in the EU 15 for active programmes is $0.55 \%$ of GDP, and for passive programmes is 1.41 : roughly a $2: 5$ ratio. In general, however, countries that are generous on one dimension tend to be so also on the other: the rank correlation across countries between expenditures in active and in passive programmes is 0.87 .

- The most "generous" countries include the four Nordic and three Continental countries $(B E, D E, F R)$. Most of these countries keep the same rank for both active and passive LMP: the two exceptions are SE (2nd in the ranking for active programmes, 10 th for passive) and DE (respectively 7 th and 3rd).

- The least generous includes the three Baltic countries and CZ, GR, RO, SK. Also in these cases each country has similar positions in both rankings.

On the other hand, if we compare generosity in LMP with strictness in EPL, the rank correlation is very low (0.27), but on the whole positive. The group of the seven "strictest" countries (index 2.5 or above), includes four which are also among the most generous ( $B E, D E, F R, S E)$. With the exception of $S E$, the other Nordic countries however are out of this group. These data are shown also in Figure 3.a, where we plot the index of EPL strictness against total expenditures on all labor market programmes (as a ratio to GDP).

[ Figure 3.a : graph_1.0.5_2005a]

Figure 3.b, instead, plots EPL strictness against a measure of standardized UB. ${ }^{9}$ The overall picture is similar between the two graphs: countries fall essentially in three groups, according to the generosity of the UB system:

- less than $25 \%$ of YPC: GR, UK, and the four Visegrad countries ( $\mathrm{CZ}, \mathrm{HU}, \mathrm{PL}, \mathrm{SK}$ );

6. Expenditure in direct job creation.

7. Expenditure in start-up incentives.

8. Expenditure in out-of-work income maintenance and support.

9. Expenditure in early retirement.

Notice that measures 1 to 7 refer to "Active", and 8 and 9 to "Passive" policies.

${ }^{9}$ In Figure 3.b, UB are measured by taking for each country the total expenditure on outof-work income maintenance and support, divided by the number of unemployed people and by that country's income per capita. 
- between 30-60\%: all the Continental countries; three Mediterranean (IT, ES, PT); two Nordic (FI, SE); IE;

- above 80\%: DK and NL.

[ Figure 3.b : graph_1.0.3_2005b]

In any case, it is hard to identify the four models suggested by Boeri. One reason might be that we have adopted different measures of UB. ${ }^{10}$ In fact, countries may differ from each other not only for the amount they allocate to each type of LMP, but also for the number and type of the intended beneficiaries. In general, not all those currently unemployed will be entitled to participate in all LMP, and some payments or benefits may accrue to those who are not currently registered as unemployed. A simple way to look at this question is to compare the number of unemployed person to the number of participants to all LMP. As Figure 4 shows, in many countries the latter group is much larger: especially so in $B E$ and $D E$, but also in all other Continental and Nordic countries, and in IE and ES.

[Figure 4: graph_0.3 ]

This graph suggests that we should look at how are participants in LMP divided between those who take part in "active" and "passive" measures. This is done in Figure 5, where both variables are measured as \% of the labor force. In addition, the size of each circle is proportional to the GDP share of all LMP expenditures for that country.

[Figure 5: graph_0.4]

Most countries fall along a 2:1 line, that is, there are approximately two participants to passive policies (mostly UB) for each participant to active policies. Along this line we find both the less and the more generous countries. ${ }^{11,12}$ As this graph makes clear, those countries, which are more generous in terms of participants to LMP, are also often more generous in terms of the share of GDP devoted to such policies, as it is shown in Figure 3 and Table 1.

10 Figure 1 (from Boeri, 2002) displays the percentage of unemployed people reporting benefits, while we have used total expenditures on LMP as percentage of GDP (Figure 3.a) and UB expenditure per unemployed divided by income per capita (Figure 3.b).

$11 \mathrm{PL}, \mathrm{SI}$, and GR are not included in the graph, but they would fit in this group too. PT, instead, would appear considerably more generous, and also with a remarkable preference for passive measures.

12 Only few countries have more participants to active than to passive LMP (that is, they fall below the $1: 1$ line). Of these, the more generous ones, in terms of participants involved, are ES and SK. 
In Figure 6, we look at the data somewhat differently: we plot the expenditure for UB (on the vertical axis), against all the labor market-related expenditures: not only active and passive LMP, but also payments for sick leave (all expenditures in GDP ratio.

[Figure 6: graph_0.2]

The main division line is again on the basis of relative generosity: in the least generous group (between 0.5 and 2.5 of GDP) we find three Mediterranean countries (GR, IT, PT), the two Anglo, and AT, CZ, HU. All the other countries spend between $3-5 \%$ of GDP on LMP, while DK is close to $6 \%$. However within each group some countries rely more on UB (GR and AT in the less generous group; DE in the more generous). On the contrary, CZ, HU and UK (among the less generous) and SE (among the more generous) allocate to UB less than $1 / 3$ of total expenditures.

Summing up, in 2005 and after the new members' accession, the EPL-UB tradeoff does not provide a useful way to summarize the different attitudes of EU members towards labor market policies. ${ }^{13}$ Instead, it seems more reasonable to distinguish essentially two groups:

- Countries with generous LMP: the four Nordic, plus BE, DE and FR, followed by $A T, E S$ and PT and, in terms of participants involved, especially for UB programmes, also IE. Within this group we find both countries with strict EPL regulations ( $P T, E S, F R, S E, B E, D E)$ and others that are very permissive (DK, $\mathrm{FI})$.

- Countries with least generous LMP: the three Baltic states and most other NMS (with PL relatively more generous), followed by GR, UK and IT. Also here we find countries with permissive EPL (UK, IE, SK, HU, CZ) and others which are very strict (GR).

On average, the beneficiaries of UB are double in number than those on other (active) LMP - except in ES, SK, BG, IT, LT, where the ratio of beneficiaries is closer to $1: 1$. However, if we look at expenditures, the budget for UB in most countries is about half of the overall budget for LMP and sick leave: hence, on average, beneficiaries of UB are treated much more cheaply relative to beneficiaries of other programmes.

\footnotetext{
${ }^{13}$ See also the econometric evidence reported below in sections 5.2.a and 5.2.d.
} 


\subsection{Equity vs. Efficiency: making room for the new entries}

Let us now turn to the equity vs. efficiency tradeoff. We update Figure 2, including 25 out of the $27 \mathrm{EU}$ members. ${ }^{14}$ Since in this case we have data over a longer period, we begin to examine the situation in 2000 (Figure 7a). Here we observe:

- The "Continental" group is now smaller: only BE and LU are still characterized by low poverty risk and low employment rate, but have been joined by HU and SI.

- DE and CZ have joined AT and the "Nordic" group (low poverty risk, high employment rate)

- The Anglo group (high poverty risk, high employment rate) continues to include IE, UK and also PT.

- Most of the new entries are in the "Mediterranean" group (high poverty risk, low employment rate): in addition to GR, ES, IT we find many NMS: BG, EE, LT, LV, $\mathrm{PL}, \mathrm{RO}$. Also FR and MT have approached this group.

In any case, the graph maintains a heuristic value, as it vividly represents the "Equity vs. Efficiency" choices of different countries, with the Mediterranean model being ineffective on both counts.

[ Figure 7.a : graph_1.1_2000]

[ Figure 7.b : graph_1.1_2000-2005 ]

However, things move, and sometimes even for the better. The race to abandon the Mediterranean model before it sinks is open, and some do succeed! Figure 7.b documents this evolution, over the period 2000-2005. Overall, the EU-15 average has moved towards the Anglo model. More specifically:

- Employment rates have increased, especially in the Mediterranean group. ${ }^{15}$

- The three Baltic countries are now in an intermediate position between the Mediterranean and Anglo groups.

- FR (back in the Continental group) is the only country that has considerably improved its position on the Equity dimension.

\footnotetext{
${ }^{14}$ Note that in passing from Fig. 2 to 7 a the vertical scale has been inverted. Also, we shall continue to name the four groups according to the Boeri-Sapir distinction, although clearly they have lost part of their geographical connotation.

15 The increase in employment rates is not related to cyclical factors. To ascertain this possibility, we recomputed the employment rates, adjusting them for the output gap (Details of the adjustment are available from the author). The resulting new graph is however not meaningfully different from Figure 7.b.
} 
- PL and RO unfortunately move out in the wrong direction, drifting towards both inefficiency and inequity.

Let us turn now to our motivating question: how do outcomes relate to the policy inputs? Let us first examine the relation between expenditure on all LMP (relative to GDP) and poverty risk (Figure 8 ). Three groups of countries stand out:

- High poverty risk, low expenditure on LMP: the three Baltic states, the four Mediterranean states, the two Anglo states, plus PL and RO;

- Low poverty risk, low expenditure on LMP: three of the four Visegrad countries (CZ, HU, SK), plus BG and LU;

- Low poverty risk, high expenditure on LMP: the four Continental and the four Nordic countries.

[ Figure 8 : graph_3.3_2005 ]

In general, Figure 8 shows a clear, negative relation between the ex-post poverty risk and the extent of expenditures on LMP, although a few countries seem to get away with good outcomes without paying the policy cost. Moreover, in relation to our previous findings, we observe that:

- Countries with a high risk of poverty (after policy transfers) belong in the group of those previously identified as least generous in terms of LMP

- All the generous countries are among those with a low (below 15\%) poverty risk (with the exception of ES).

In addition, expenditures on LMP are also positively (albeit weakly) associated with employment rates (Figure 9). Instead, the relation between expenditures on LMP and unemployment rates exhibits a wider dispersion (Figure 10). ${ }^{16}$ However the overall impression is of a negative relation, thus pointing to the fact that LMP do not appear to encourage unemployment, or to contrast the attainment of high employment rates.

$$
\begin{gathered}
\text { [ Figure } 9: \text { graph_3.8_2005 ] } \\
\text { [ Figure } 10: \text { graph_3.13_2005a ] }
\end{gathered}
$$

Other indicators of labor market policies, instead, exhibit a less favorable relation with labor market outcomes. For instance, Figure 11 depicts a weak but negative

\footnotetext{
${ }^{16}$ The same relation emerges if, instead of payments for all LMP, we consider only UB.
} 
association between the Union Protection Index and employment rates, and Figure 12 gives no evidence of any degree of association between EPL and employment rates.

[ Figure $11:$ graph_3.10_2005]

[ Figure 12 : graph_3.9_2005 ]

These graph point to the fact that, contrary to LMP, purely defensive policies, that attempt to "rule out" supposedly labor-unfriendly behavior, are not associated with positive employment outcomes. On the contrary, Figures 13 and 14 show that, if anything, they are associated with unfavorable unemployment outcomes

[ Figure 13 : graph_3.15_2005 ]

[ Figure 14 : graph_3.14_2005 ]

\subsection{Summing up}

A few facts seem indeed to have emerged from our search:

- Labor market policies are quite different across EU members. And, although of course labor market insiders may still be fighting to defend or secure EPL, the extent of this protection does not seem to be a major discriminant. Instead, a simple way to characterize countries is in terms of overall policy generosity. Generous countries such as the Nordic and Continental countries plus Spain have broadly similar policies, in terms of both policy coverage (which extends beyond the number of the currently unemployed) and of policy generosity (LMP expenditures relative to GDP). However, within this group, some are leaning more towards the use of UB (like Germany), others towards active policies (like Sweden).

- In terms of policy outcomes, the equity-efficiency paradox noticed by Sapir (2004) still appears. In particular, countries with a high poverty risk generally are also characterized by low employment rates. In this group or close to it we find Greece, Italy and most NMS (with the exceptions of the Czech Republic and Slovenia). All of which are among the less generous countries ...

- ... which brings us to notice a negative relation between the ex post poverty risk and expenditures on LMP. More precisely, three groups of countries emerge: High poverty risk, low expenditure on LMP (the three Baltic states, the four Mediterranean states, the two Anglo states, plus PL and RO); Low poverty 
risk, low expenditure (three of the four Visegrad countries - CZ, HU, SK), BG and LU); Low poverty risk, high expenditures (the four Continental and the four Nordic countries).

- In particular, however, countries which are more "generous" in terms of LMP seem also the most successful at reducing poverty risk. Spain and Portugal provide an exception to this fact.

\section{$\underline{2.5}$ Wither convergence?}

Figure 7.b points to the fact that countries do "move"; that is, within our period of observation they have modified their policies and possibly also their performance. A natural question to pose is: do such moves point to a pattern of convergence? Are countries implicitly coordinating towards the acceptance of one de facto "European" social model? On these issues, we may observe that:

- Most NMS (with the exception of the wealthier ones) featured in 2000 some aspects which rendered them affine to the Mediterranean model. Probably this was more a matter of fact (that is, of initial conditions) than of choice. But in general most countries have shown a tendency to move out of that model (the "sinking ship"), towards the Anglo model.

- The Continental model is on the move, and on many accounts Belgium, France and Germany (as well as Austria and the Czech Republic) have adopted some of the efficiency-improving features of the Nordic models. Spain is also moving in the same direction.

[ Table 2 ]

- At the same time, also the Anglo model has been evolving. This appears especially true for Ireland. Nevertheless, in reference to LMP, the differences between the Ireland and UK and most Nordic and Continental countries persists. This point is confirmed if we look also at other labor market-related policies, as it is done in Table 2, which has been drawn on the basis of Zhou (2007). While some of the differences (such as the lower tax wedge) point in favor of the 
Anglo countries, others place the Nordic countries in a more favorable light. In any case, the two group of countries still seem rather apart from each other. ${ }^{17}$

To end this part on a more careful note, however, the evidence we have looked at does not necessarily suggest that all that matters is for each country to find and possibly adopt the "best" social model. A good social model is expensive (as the Nordic experience proves), but it can produce good results and support a high degree of participation to the labor market if it is also coupled with other policies and institutions. It is up to these policies and institutions to generate sufficient incentives and mobilize enough resources, which in turn are conducive to high and increasing levels of employment, productivity and technological progress. Perhaps it is also in some of these characteristics ${ }^{18}$ that lay the secrets of the Nordic success.

\section{Policies, institutions and outcomes: a framework for our hypotheses}

In section 2 we have searched for correlations between labor markets outcomes and policies, which we identified on the basis of a graphical analysis. In this section we use a simple econometric model to test for the same correlations, while taking into account other variables, which are likely to influence the relation between policies and outcomes. In the previous section, in particular, we have focused on policy generosity as a meaningful characterization of different policy stances. However, we must acknowledge that there are widely different opinions on the question of how to interpret the consequences of policy generosity. For instance:

17 There are other dimensions of social policies, which are not directly related to labor markets, but which have nevertheless an indirect impact on it. In this paper we have not examined them. This may be relevant in particular in respect of the UK. If we look at total social expenditures as \% of GDP, the UK ranks 16th out of the 19 countries included in the OECD Dataset. At a more disaggregated level, it ranks 8th in terms of social expenditures towards the family, and 1st in terms of housing expenditures (in-kind benefits). Thus it might well be the case that, for the UK, these polices are an efficient substitute for LMP, and that they might have contributed to ensure high employment rates. Nevertheless it remains true that on the basis of several measures of social outcomes (poverty rates, inequality measures) the UK still performs distinctly worse than the Nordic countries.

18 These include informal institutions, such as the "civicness" so often referred to in expositions of the Danish welfare system. It also includes policies that lead to deregulation of product markets, high levels of R\&D expenditures, which promote the importance and quality of scientific training and the ability of the financial sector to promote the growth of innovative firms. Some of these aspects are discussed in the EAAG Report (2007), chapter 4. 
"There are polar positions on the effectiveness of active labor market programs. On one hand, proponents of these programs argue that active labor market programs are both necessary and useful, short only of a panacea for reducing unemployment and protecting workers. Opponents of the programs tend to summarily dismiss these programs as a waste of public money with high opportunity costs to other social programs and labor market efficiency as a whole. Based on a thorough evaluation of evidence, this paper shows that some programs can be useful to some workers in some cases." (Dar and Tzanattos, 1999)

This cautious approach is maintained by many observers, even today, and perhaps even reinforced despite the large amount of additional empirical evidence that has been accumulated since. We do not attempt a full review of the literature here. Instead, we propose a synthesis of few recent, representative conclusions:

1) Bassanini and Duval (2006, p.6) argue that "changes in policies and institutions appear to explain almost two thirds of non-cyclical unemployment changes over the past two decades. ... On average, it is estimated that a 10 percentage point reduction in the tax wedge, a 10 percentage point reduction of unemployment benefits and/or a decline in product market regulation by two standard deviations would be associated with a drop in the unemployment rate by about 2.8, 1.2 and 0.7 percentage points, respectively".

(2) On unemployment benefits, a different opinion is put forward by Howell, Baker, Glyn and Schmitt (2007, p.40). They suggest that the positive correlation often observed between unemployment and gross benefit replacement ratios should be interpreted as causality running from the former to the latter.

3) On Active Labor Market Programs (ALMP), Betcherman, Olivas and Dart (2004, p.52) observe that "some ALMPs do have positive impacts, with favorable costbenefit ratios. However, in many cases, programs have not improved the future employment prospects of participants and, when they have, they have not always done so in a cost-effective manner. ... Employment services are generally the most cost-effective intervention: employment and earnings impacts are usually positive and, compared to other ALMPS, these employment services are inexpensive. Training programs for the unemployed can also have positive impacts on employment, though usually not on earnings. These programs are most effective when they are workplace-based." 
4) On the relation between UB and other LMP, (Bassanini and Duval, 2006, p.6) observe that "the impact of generous unemployment benefits on unemployment appears to be mitigated by high public spending on ALMPs, perhaps because high spending on ALMPs is often accompanied with strong emphasis on 'activation'".

5) Finally, "most of the individual country studies demonstrate that regulations promoting job security ... on net reduce employment" (Heckman and Pagés, 2003, p.6).

On the basis of our reading of the (mostly micro-based) available literature, we thus state our working hypotheses as follows:

- We expect ALMP to exert a positive effect on labor market outcomes (that is, a positive impact on employment and participation rates, and a negative one on unemployment). On the other hand, although it has often been ascertained that the size and cost-effectiveness of such effects may vary according to the type of program and also to cyclical conditions, we shall not discuss these aspects, as our aggregate framework of analysis would not be appropriate for such more detailed enquiries.

- We are more neutral about the effect of passive LMP (such as unemployment benefits). While they are certainly expected to raise the overall participation rate, it has been widely argued that they can either encourage or discourage the search for employment, so their effect could be ambiguous. However, as we remarked earlier on (section 2.2.1) "The rank correlation across countries between expenditures in active and in passive programmes is 0.87 ". Hence the remark by Bassanini and Duval (2006) that "the impact of generous unemployment benefits on unemployment appears to be mitigated by high public spending on ALMPs" could be quite appropriate in our sample. Overall, if only because of this correlation, it is possible that also UB appear to have a positive impact on labor market outcomes.

- Moreover, unemployment benefits programmes are defined by a large number of parameters, that specify entitlements, conditionality, duration, and replacement rates. Given the aggregate nature of our analysis, we can condition labor market outcomes only on overall expenditure and/or number of participants. Thus we will not be able to discriminate on the basis of more 
precise distinctions between the UB programmes available in different countries.

- We expect regulations that either enhance labor markets' rigidity, or that more generally are likely to shift downwards the firms' demand for labor to have a negative impact on labor market outcomes.

Finally we observe that, although the interactions of policies and institutions with each other and also with cyclical conditions have often been discussed in the literature, our framework is not well suited for an empirical exploration of these issues. Accordingly, we shall not report on them.

Summing up, in Box 2 we present the basic model structure, which will be used to examine empirically the validity of our hypotheses.

\section{Box 2}

\section{A basic model to compare Labor Market Policies across countries}

A general specification of the basic model is:

$$
\text { Outcome }_{\mathrm{i}, \mathrm{t}}=\alpha_{0}+\sum_{\mathrm{k}}^{\mathrm{K}} \alpha_{1, \mathrm{k}} \operatorname{INST}_{\mathrm{k}, \mathrm{t}}+\sum_{\mathrm{j}}^{\mathrm{J}} \alpha_{2, \mathrm{j}} \operatorname{LMP}_{\mathrm{j}, \mathrm{t}}+\mathrm{g}_{\mathrm{t}}+\varepsilon_{\mathrm{i}, \mathrm{t}}
$$

where:

Subscript $\quad \mathbf{i}=1, \ldots, 27$ (the EU Member States).

Subscript $\quad \mathbf{t}=$ time.

Outcome: either: Employment rate (Employed persons aged 15-64 as a share of the total population of the same age group);

or: Unemployment rate (Unemployed persons as a share of the total active population);

or: Activity rate (Active persons as a share of total population 15$64)$.

INST $_{k, t} \quad$ country-based indicators of institutional or policy characteristics likely to condition labor market outcomes.

$\mathbf{L M P}_{\mathbf{j}, \mathbf{t}} \quad$ country-based measures of Labor Market or Social Policies, alternatively defined to include different types of expenditures on, or participants to policy programmes.

gt time fixed effects. 


\section{Policies and outcomes: cross-country evidence}

In this section we describe in some detail the results of the estimation of the basic model. In section 4.1 we examine some time-series characteristics of the data and discuss their implications for the definition of our samples. In sections $4.2,4.3$ and 4.4 we report on the estimates for the employment, unemployment and activity rates respectively.

\section{$\underline{4.1 \text { Data and estimation strategy }}$}

Our analysis is based on the estimation of different specifications of the basic model described in Box 2. One of our aims is to take into account as many EU members as it is feasible. The data available at Eurostat make such a comparative analysis now feasible for the first time, at least in certain dimensions, but only for the more recent years. ${ }^{19}$

On the other hand, the New Member States (NMS) which acceded the EU in 2004 and 2007 where also (with the exclusion of Cyprus and Malta) transition countries. Hence, the evolution of their labor markets throughout the nineties is largely idiosyncratic relative to the older EU members, and thus unlikely to be captured by the same specification, even in the few cases for which we have data. In this respect, the constraint that most data are available only since 2000 is germane to the our desire of adopting the same modeling framework for all the EU-27 Members.

A first look to the data immediately also shows that, for most of the countries involved, there is very little variation in the time-dimension as far as labor market outcomes are concerned. Thus, even within the short sample of six years for which data are available, there is little hope to conduct a meaningful panel analysis: in this case, country fixed effects are likely to pick up all the variability of the data. ${ }^{20}$

Similarly, when we examine the right-hand-side variables, we notice that several institutions or policies are either constant or very infrequently measured throughout the period. These characteristics of the data set suggest that we should

19 Our full sample will span from the year 2000 onward. Longer time series are available, for the dependent variables, only for a subset of the EU members.

${ }^{20}$ A yearly panel regression for any of the listed dependent variables on the only set of country (or country and time) fixed effects yields very high R-squared (not shown). 
model the data essentially in the cross-country dimension. In particular we run, and will report on, regressions with the following time-dimensions:

- averages of yearly data (2000-2005);

- 2-period pooled data, with each period defined as average of yearly data (2000-02 \& 2003-05, respectively). ${ }^{21}$

We shall describe below in some detail only some of the series of specifications used. As it will be appear from the robustness checks in section 5, in general results change only marginally when the specification is changed to accommodate different definitions or measures of the explanatory policy variables, and also alternative institutional measures (employment protection legislation, product market regulation and tax wedge).

\subsection{A first model for the employment rate}

We explain the employment rate (as well as Unemployment and Activity rates, see sections 4.3 and 4.4 ) as a function of alternative, different measures of LMP expenditures, in ratio to GDP:

1. Sum_LMP_1-9, all Labour Market Policies:

$\left[\sum_{k=1}^{9} L M P_{k, t}\right]$

2. Sum_LMP_1-7, all Active LMP:

$\left[\sum_{k=1}^{7} L M P_{k, t}\right]$

3. Sum_LMP_2-7: all Active LMP, except Market Services: $\left[\sum_{k=2}^{7} L M P_{k, t}\right]$

4. LMP_8: only Unemployment Benefits:

$\operatorname{LMP}_{8, t}$

5. Sum_LMP_8-9: U. Benefits + Early Retirement: $\left[\sum_{k=8}^{9} L M P_{k, t}\right]$

${ }^{21}$ In addition we also run regression for the two separate halves of the sample (averages of yearly data 2000-2002 and 2003-2005, respectively). In these cases results never contradict those in the other time samples, except for the lower significance or insignificance of some explanatory variables, which we impute to reduced efficiency. These results are available on request. 
In order to characterize the different rigidity of labor market conditions across countries, we also include in all specifications the variable Rig_Emp, which measures the rigidity of employment conditions ${ }^{22}$.

We expect LMP measures to have a positive effect, and the rigidity measure to have a negative effect on employment rates.

[TABLE 3.1 ]

Results are shown in Table 3.1, and they are robustly similar for all the reported specifications: higher employment rates are generally associated with higher expenditures on all alternative measure of LMP, and negatively associated with employment rigidity, although the limited number of observations dampens efficiency. ${ }^{23}$ The policy measure which always ensures the (marginally) highest fit as well as the highest quantitative impact on employment is the most inclusive measure of Active policies (Sum_LMP_1-7).

\subsection{A model for the unemployment rate}

In analogy to the previous section, we model the unemployment rate as a function of the same independent variables used for the employment rate. In this case we expect the LMP measures to have a negative effect (unless the generosity of certain policies should actually encourage unemployment), and the rigidity measure to have a positive effect on the dependent variable.

Results, which are shown in Table 3.2, broadly confirm our expectations. However, they should be interpreted in light of the a-priori ambiguity of the effects of certain LMP on the unemployment rate. We find that the estimated equations have a distinctively worse fit than the previous ones and not all estimated coefficients are significant. Also, the estimated value of significant coefficients shows that the absolute impact of LMP on unemployment is much reduced relative to the employment equations.

22 The Rigidity of Employment Index is available from the Doing Business/World Bank dataset (http://www.doingbusiness.org/). It is computed as the simple average of three indicators (Difficulty of Hiring, of Firing and Rigidity of Hours).

${ }^{23}$ The model is estimated with 15 observations for the first period and 23 for the second. Although some countries are represented in the LMP dataset for only some types of policy expenditures, Cyprus Malta and Slovenia are never represented and thus are excluded from all samples. 
[ TABLE 3.2 ]

\subsection{A model for the activity rate}

In this section, we explain the overall activity rate (i.e. the degree of participation to the labor market) again as a function of LMP expenditures and of labor market rigidity. We expect the LMP measures to have a positive effect and the rigidity measure to have a negative effect on the dependent variable.

Results are shown in Table 3.3. They fully confirm the expected signs of all the different measures of LMP, although they have a looser fit than those for the employment rate.

\section{[ TABLE 3.3 ]}

\section{Robustness and specification checks}

In this section we report on several robustness and specification checks, which we have conducted to explore the possible role of outliers and to compare the different significance and interpretation of various institutional and policy variables.

\subsection{The role of outliers}

As a first check of the reliability of our results, we have explored the potential role of outliers. Thus we have re-estimated the best fitting or "favorite" equations from Tables 3.1-3.3 (that is, eqs. 2 and 7) by alternatively excluding each one of the countries in the initial sample, and then also by alternatively excluding each one of the following seven groups: Mediterranean; Nordic (incl. Netherland); Continental; Anglo; Baltic; Visegrad and Slovenia; Bulgaria and Romania). In the first case (one exclusion at a time), results are almost identical to those on the whole sample. In the second case - a much tougher test indeed! - only the exclusion of the Nordic group renders the estimate of the LMP coefficient not significant, whereas the Rig_Emp variable retains the same coefficient and significance. ${ }^{24}$

\footnotetext{
${ }^{24}$ Results available on request.
} 


\subsection{The Use of Different Institutional Variables}

In the empirical literature, a battery of institutional variables possibly correlated with labor market outcomes have been used to model the employment or unemployment rate. In addition to the rigidity of employment measure which we have used so far, other variables which have been used in other works include: the employment protection legislation (EPL), product market regulation (PMR) and the tax wedge (TW). Below we briefly report on the results of using these measures within our basic model. In general, the high correlation between some of these different measures, together with the limited degrees of freedom, does not allow us to run a comprehensive "all institutions" or horse race regression. Figures 15 and 16 plots the PMR variable against Rig_Emp and EPL respectively.

[ FIGURE $15-16$ ]

\section{a. Employment Protection Legislation}

In tables 4.1 to 4.3 we substitute a measure of EPL ${ }^{25}$ to Rig_Emp in all the regression for the basic model. While the LMP measures retain in these new regressions the same significance and estimated coefficients observed in Tables 3.1-3.3, the new variable instead is never significant. This result could be due, at least in part, to the fact that the new regressions necessarily exclude 5 countries previously included. However if we re-estimate the equations in Tables 3.1-3.3 excluding those 5 countries, results are barely affected: hence we conclude that the EPL measure does not have explanatory power within our simple model.

[ TABLE $4.1-4.3$ ]

\section{b. Product Market Regulation}

In tables 5.1-5.3 we introduce a measure of PMR in all the regression for the basic model, replacing the labor market rigidity measures. This follows the evidence on the role of this variable in Bassanini and Duval (2006). The new variable has a strong explanatory power and significance level in all regressions. As expected, the estimated coefficient is significantly negative for the employment and activity rates, positive for unemployment. LMP measures always retain a strong significance in these regressions (see tables). If instead we reintroduce the

25 EPL is computed by the OECD, and it is available for 1998 and 2003 only, and - unlike Rig_Emp - it is available only for 18 EU member countries. 
measures of labor market rigidity (Rig_Empl or EPL) in these new regressions, the estimated coefficients on the latter variables are non significant, and the explanatory power of the regression does not increase (results not reported).

[ TABLE $5.1-5.3$ ]

\section{c. Tax Wedge}

The regressions reported in Tables 6.1 to 6.3 include a measure of the Tax Wedge (TW) within the basic model, replacing the labor market rigidity variables. In general, results are in line with those in the previous regressions: in most equations for employment, the TW coefficient is significantly negative, and positive in those for unemployment. It is not significant in the equations for the activity rate. In all these instances, the LMP variables are strongly significant, and with the usual signs. However, when we include TW together with labor market rigidity (Rig_Emp), the former becomes no longer significant, whereas both Rig_Emp and the LMP measure retain coefficient values and significance levels similar to those reported in Tables 3.1-3.3.

[ TABLE $6.1-6.3$ ]

\section{d. Alternative measures of LMP}

In all regressions examined so far, LMP was measured as the ratio of total expenditure on each policy program to GDP. We have also experimented with two alternative measures: the total number of participants to each policy programme or the expenditure per participant as a ratio of each country's GDP per capita. Substituting these measures in the same set of regressions reported in section 4, in each case they were never significant (while the rigidity measure, Rig_Emp, always retained its significance) ${ }^{26}$. We thus conclude that measuring LMP as the ratio of expenditures to GDP yields the most significant results in our context. This is in contrast to what is reported by Bassanini and Duval (2006), who instead measure LMP as the GDP ratio of expenditures per participant to each policy program.

\section{e. Substituting LMP with wider measures of social policies}

One possible objection to the results obtained so far is that the our LMP variables may in reality be acting as a proxy variable for social expenditures more inclusively

\footnotetext{
${ }^{26}$ Results not reported in the paper, available on request.
} 
defined. To check if this objection is correct, we used the OECD data for both labor market and other social policy expenditures. ${ }^{27}$ Notice that the OECD data are available for only $18 \mathrm{EU}$ countries, and that to date there are no observations after 2003. For this reason, in order to have more data, we extended our observations backwards to 1998. On this different sample, first we run the same regressions already reported in Table 3.1-3.3 (results broadly unchanged, not reported here) then we substitute the Eurostat measures of LMP with the following policy measures from the OECD dataset:

- active policy programs (ALMP);

- unemployment benefits (UB) ;

- ALMP + UB;

- ALMP + UB + Family + Housing social expenditures;

- Total expenditure on social policies. ${ }^{28}$

\section{[ Table 7 ]}

In Table 7 we show, for sake of brevity, only some representative results: we focus on the equation for the employment rate for the pooled two-period samples (ave.1998-2000 and ave.2001-2003). Equation 1.a uses as a benchmark the Eurostat policy measures: hence it basically replicates Equation 7 from Table 3.1 in the new, two-period sample, but using all countries available for that period in the Eurostat dataset. Eq. 1.b is the same, except that it uses (with Eurostat data) only the countries in the OECD dataset for which we also have Eurostat data; Eq. 2 substitutes the Eurostat measure of ALMP with the corresponding OECD one; and the following equations use the other OECD policy indicators listed above.

Results for eqs. 1.a, 1.b, 2 are very similar, in terms of significance and fit. However, when we use UB in place of ALMP the statistics begin to deteriorate significantly. Also, when using wider measures of social expenditures we obtain poor significance, much lower point estimates, and very low overall goodness of fit.

From this results we conclude that it is really the measure of Active LMP that, together with employment rigidity, drives home the best results. Equations using

\footnotetext{
27 The OECD collects data on labor market policies with a classification similar to, but not identical with that of Eurostat. These data are available only for a subset of all EU members. In addition, the same dataset contains data on non-labor market related social policy programmes.
}

${ }^{28}$ All variables are measured as a ratio of each country's GDP. 
either the activity rate or unemployment as the dependent variable conform to the same pattern of results (available on request).

\subsection{Interpretation of the results.}

Results obtained so far point to the fact that LMP, and especially active policies, exhibit a positive partial correlation, in a cross-section of EU countries, with employment and activity rates, and a negative one with unemployment rates. To interpret this correlation in terms of statistical causality we should check against the possible non-predetermined-ness of the regressors. Although we attempted to do that, ${ }^{29}$ we do not think it can be done satisfactorily due to the short observation period and the fact that institutional variables and policy measures move very little through time.

We resort instead to some tentative logical arguments:

- If policies are caused by the outcomes of the labor market, then we should expect to see that low employment or high unemployment induce, and hence are associated with, higher expenditures, possibly both on active and passive programs. Instead we observe the opposite. ${ }^{30}$

- If the evidence we find for the role of active LMP, and to some extent also for passive policies, were simply the result of the fact that countries with high levels of per capita income generally exhibit also higher levels of employment and (at least in Europe) more extended welfare states, then we would expect to find an even closer association between wider measures of the welfare state and employment rates: instead, as we document in Table 7 , we observe the opposite.

${ }^{29}$ To this purpose, we first regressed the policy variables on the average employment rates of the first period (2000-2002), then used the residuals from this regression in place of the policy variables as regressors for the second period employment rates. These regressions run into two problems: the persistence of employment rates between the two periods, and the fact that each stage regressions could be run only on a small number of observations (17 countries).

30 On the other hand, we cannot rule out in principle that successful labor market performance (high employment, low unemployment rates) might induce countries to adopt more expensive LMP. However we think that there are good reasons, both in theory and in practice, why this is unlikely to be observed. Also notice that the argument in the text cannot be used also to explain the correlation between measures of institutional rigidity and employment outcomes. 
Hence, even without the comforting evidence of properly devised tests of predetermined variables or IV estimation, we are inclined to believe that our equations should be interpreted as evidence that more expenditure on LMP will result in a better performance of the labor markets.

\section{Conclusions}

In this paper we show that labor market policies are quite different across EU members, and we suggest a simple, although clearly not exhaustive way to characterize this difference in terms of policy generosity (the size of LMP expenditures relative to GDP). In this respect, both the graphical inspection of the data and the econometric analysis suggest that higher rates of employment are associated with higher expenditures on labor market policies, especially on active policies on the one hand, and a lower degree of rigidity in labor market institutions on the other.

More precisely the findings of the econometric analysis, which refer in general to 23 EU member states for the period 2000-2005, can be summarized as follows:

- Measures of active LMP are generally associated with higher rates of employment and activity, and lower rates of unemployment. ${ }^{31}$

- Measures of passive LMP (Unemployment benefits) are also generally associated with higher rates of employment and activity, and lower rates of unemployment, but the point estimates indicate a lower effect per amount of expenditure relative to active programs. One interpretation of this finding is that inefficiently designed UB programs may reduce the incentives to search for employment, but that, given the correlation between active and passive expenditures, our data really pick up the (overall positive) interaction of different policies. Clearly this interpretation needs to be supported by further research.

- Wider measures of labor market-related or social expenditures are in general less significantly related to labor market outcomes.

31 These results support the evidence put forward by De Grauwe and Polan (2005), that well-developed welfare systems do not necessarily place a burden on economic performance. 
- Even in the absence of formal tests of predetermined variables or of IV estimates, we are inclined to believe that our equations can be interpreted as evidence that more expenditure on LMP, especially on active programs, will result in a better performance of the labor markets.

- Among institutional variables, the two which exhibit a stronger significance and explanatory power in our equations are Rigidity of employment (as defined and measured in the Doing Business / World Bank dataset) and Product Market Regulations (OECD). Both affect labor market outcomes negatively. When both measures are included, although clearly the latter is more indirectly linked to such outcomes, it nevertheless dominates.

The last observation suggests some useful directions for further research. The dominant role of Product Market Regulations may be due to the fact that, while labor and product market regulations and rigidities are strongly correlated across countries, PMR might have an additional, negative effect on the total factor productivity of the regulated firms. In particular, PMR may also direct firms' investments away from the innovative sectors, where employment growth is more likely to be located. ${ }^{32}$ Thus the way in which the two sets of regulations interact is possibly complex, and needs to be understood in more detail.

The main advantage of the format of analysis adopted in this paper is that it allows us to document and systematically compare, for the first time, labor market outcomes and policies in both old and new EU member states. On the other hand, the aggregate nature of our data, and the fact that they are available only for the most recent years, entails several limitations, which will have to be overcome by future work. In particular it would be important to employ measures of LMP that take into account not only the sheer dimension but also the different design, induced incentives and hence also efficiency, of the policies adopted in different countries.

\footnotetext{
${ }^{32}$ See Nicoletti and Scarpetta (2005).
} 


\section{References}

Bassanini, Andrea; and Duval, Romain (2006) "Employment Patterns in Oecd Countries: Reassessing the Role of Policies and Institutions". OECD Economics Department W.P. 486.

Bertola, Giuseppe; Jimeno, Juan Francisco; Marimon, Ramon; and Pissarides, Christopher (2001) "Welfare Systems and Labor Markets in Europe: What convergence before and after EMU?". In: Giuseppe Bertola, Tito Boeri e Giuseppe Nicoletti (eds.) Welfare and Employment in a United Europe, Cambridge: Mit Press. Working paper version: http://www.frdb.org/documentazione/scheda.php?id $=53 \&$ doc $\mathrm{pk}=9046$

Betcherman, Gordon; Olivas, Karina; and Dar, Amit (2004) "Impacts of Active Labor Market Programs: New Evidence from Evaluations with Particular Attention to Developing and Transition Countries". World Bank - Social Protection D.P. 04.02

Boeri, Tito (2002) "Let Social Policy Models Compete and Europe Will Win". Unpublished paper.

Dar, Amit; and Tzannatos, Zafiris (1999) "Active labor market programs: a review of the evidence from evaluations". World Bank - Social Protection D.P. 99.01.

De Grauwe, Paul; and Polan, Magdalena (2005) "Globalization and Social Spending" . Pacific Economic Review, 10(1, pp. 105-123.

EEAG (European Economic Advisory Group) (2007). Report on the European Economy 2007. Cesifo. http://www.cesifo-group.de

Eurobarometer survey (2007) "European social reality". Special Eurobarometer 273, February. http://ec.europa.eu/public opinion/archives/ebs/ebs 273 en.pdf

European Convention (2003). "Contribution by the UK, Spanish and Estonian government representatives". Working Group XI "Social Europe", Working Document 13, January. http://european-convention.eu.int/docs/wd11/6477.pdf

Ferrera, Maurizio (1998) "The Four 'Social Europes': Between Universalism and Selectivity". In Rhodes, Martin; and Yves Meny (eds.) The future of European welfare: a new social contract?, Basingstoke: Macmillan. 
Heckman, James; and Pages, Carmen (2003) "Law and Employment: Lessons from Latin America and the Caribbean". NBER w.p. 10129.

Howell, David R.; Baker, Dean; Glyn, Andrew; and Schmitt, John (2207) "Are Protective Labor Market Institutions at the Root of Unemployment? A Critical Review of the Evidence". Capitalism and Society, The Berkeley Electronic Press, 2(1), Article 1.

Nicoletti, Giuseppe; and Scarpetta, Stefano (2005) "Regulation and economic performance: product market reforms and productivity in the OECD". OECD Economics Department W.P. 460.

Riboud, M., C. Sanchez-Paramo and C. Silva-Jauregui (2002) "Does Eurosclerosis Matter? Institutional Reform and Labour Market Performance in Central and Eastern European Countries in 1990s", World Bank Social Protection Discussion Paper Series.

Rovelli, Riccardo (2007) "One market, how many social models? Policy and performance indicators for the EU-27". Unpublished, May. http://www2.dse.unibo.it/rovelli/RR-Papers/RR OneMkt ManyModels.pdf

Sapir, André (2006) "Globalization and the Reform of European Social Models". Journal of Common Market Studies, 44 (2), pp. 369-390.

Zhou, Jianping (2007) "Danish for All? Balancing Flexibility with Security: The Flexicurity Model". IMF Working Paper no. 07/36, February.

\section{Appendix: The Data}

For the purpose of this and subsequent research we have assembled a data set for the EU-27 members, based on several sources available through the Internet. The sources used for the calculations and the figures presented in this paper are:

Eurostat (http://epp.eurostat.ec.europa.eu): National Accounts and Public Finance data. Growth rates. Structural indicators on innovation and research, education, employment, unemployment, inequality and social cohesion, market integration and business demography. Expenditure and participants to labor market programmes.

OECD (http://stats.oecd.org/WBOS/Default.aspx): Expenditure on labor market programmes and EPL indicators.

European Bank for Reconstruction and Development (http://www.ebrd.com/country/sector/econo/stats/index.htm): Transitional indicators on privatisation, restructuring, liberalisation, and other reforms.

World Bank - Doing Business (http://www.doingbusiness.org/EconomyRankings/) Data on ease of doing business, of employing workers and of paying taxes. 


\section{FIGURES}

Figure 1

The EPL / UB Trade-Off

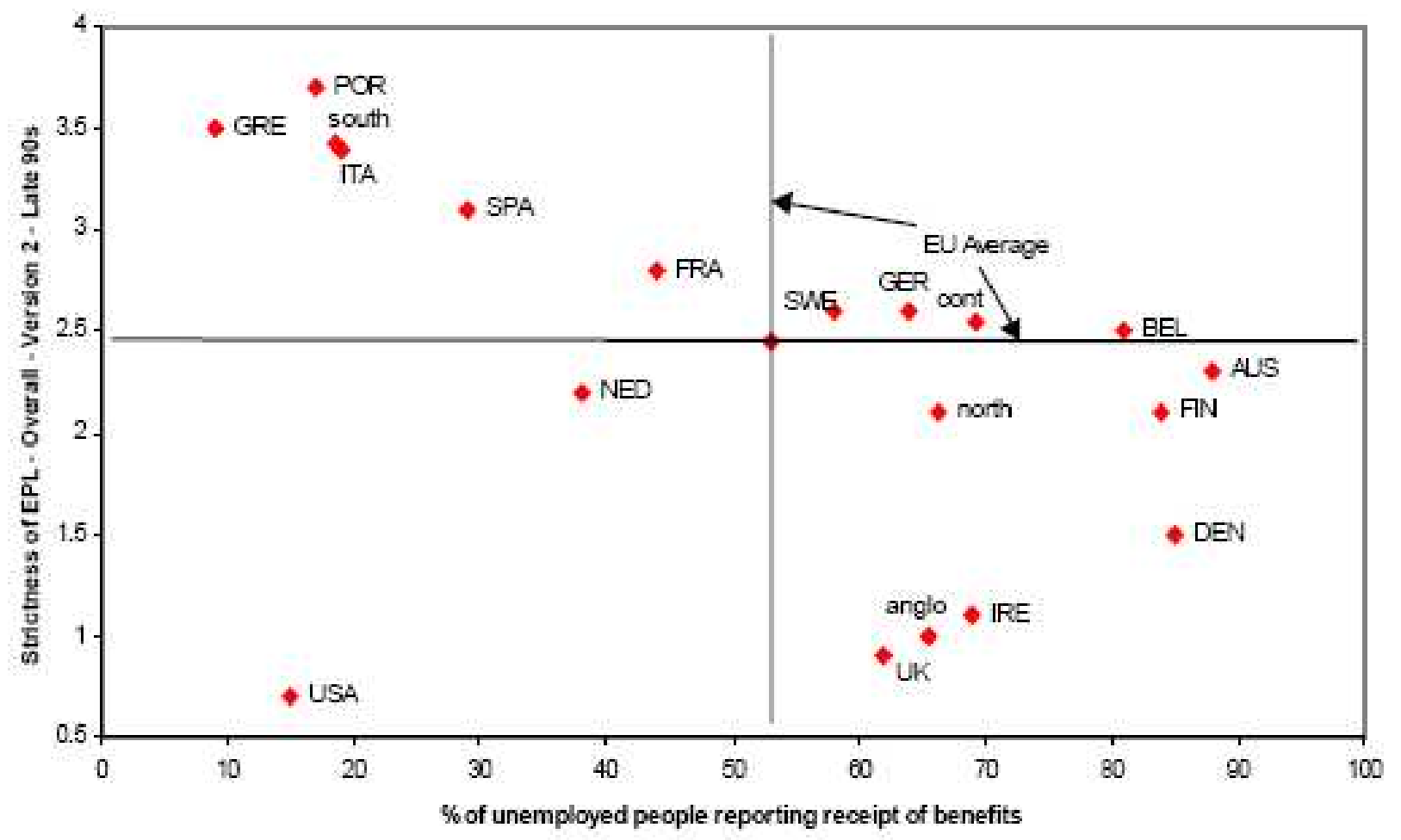

Source: Boeri (2002)

Figure 2

The Equity / Efficiency Trade-Off

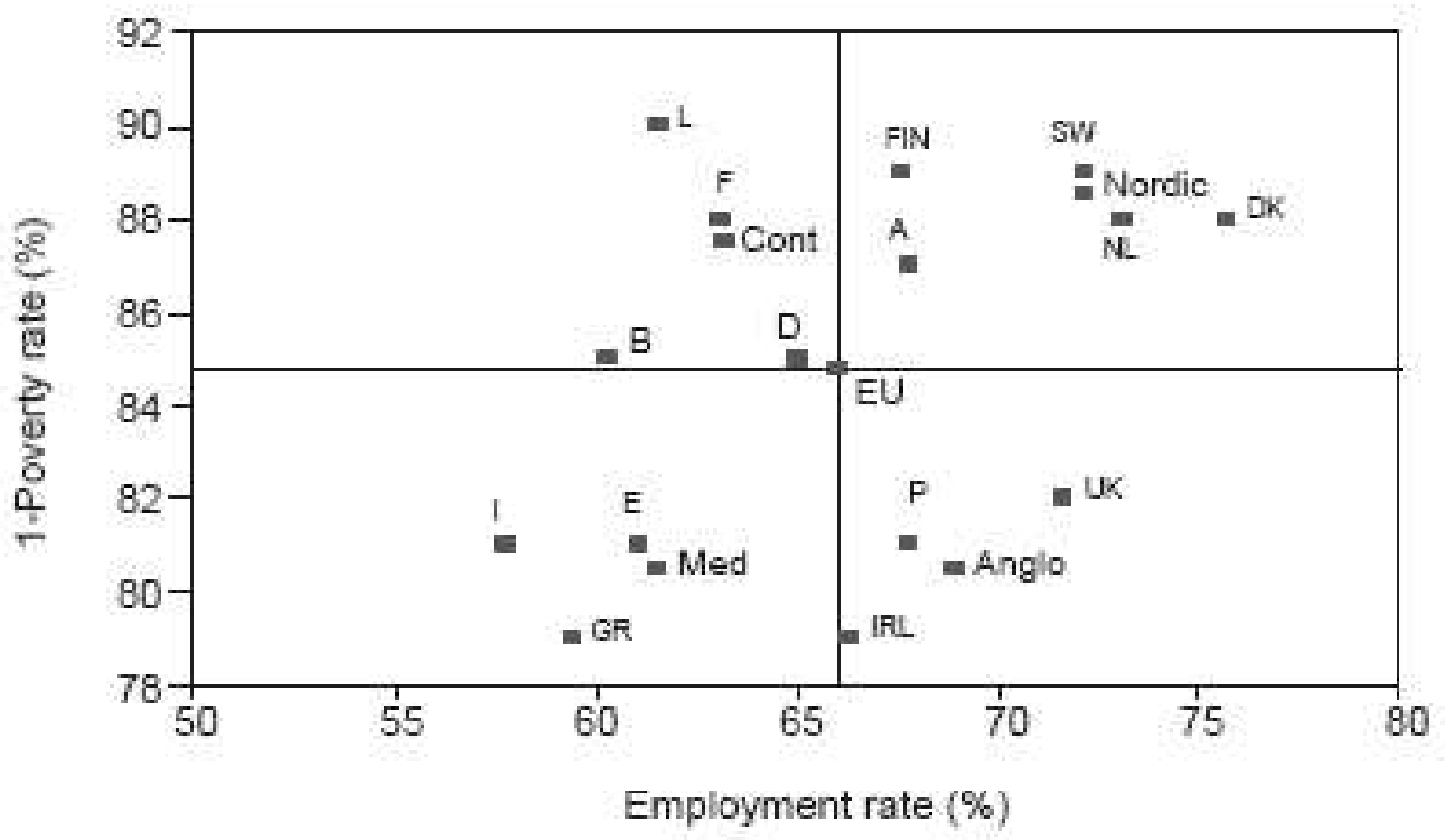


Source: Sapir (2004)

Figure 3.a

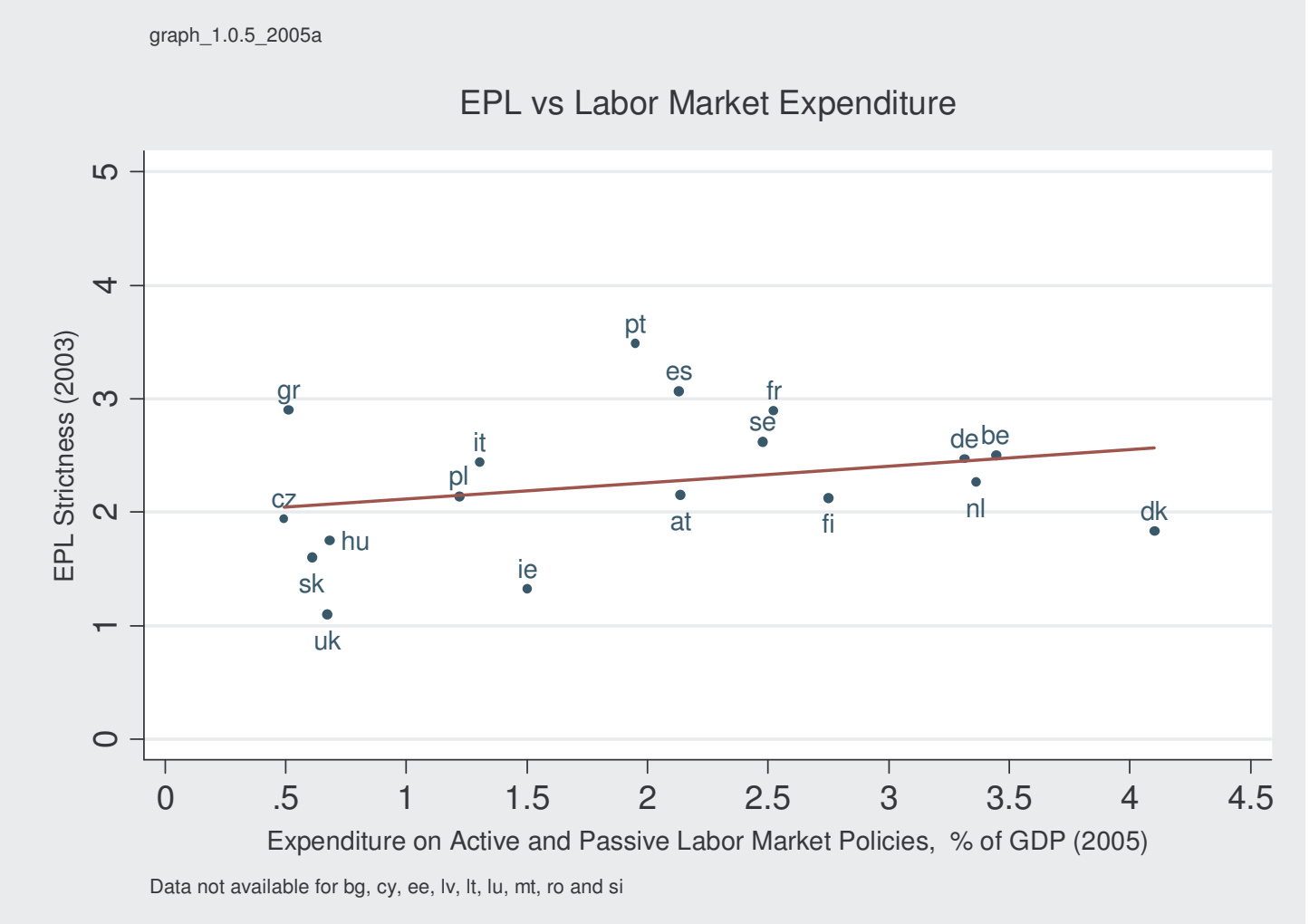

\section{Figure 3.b}

graph_1.0.3_2005b

EPL vs UB expenditure per Unemployed relative to YPC

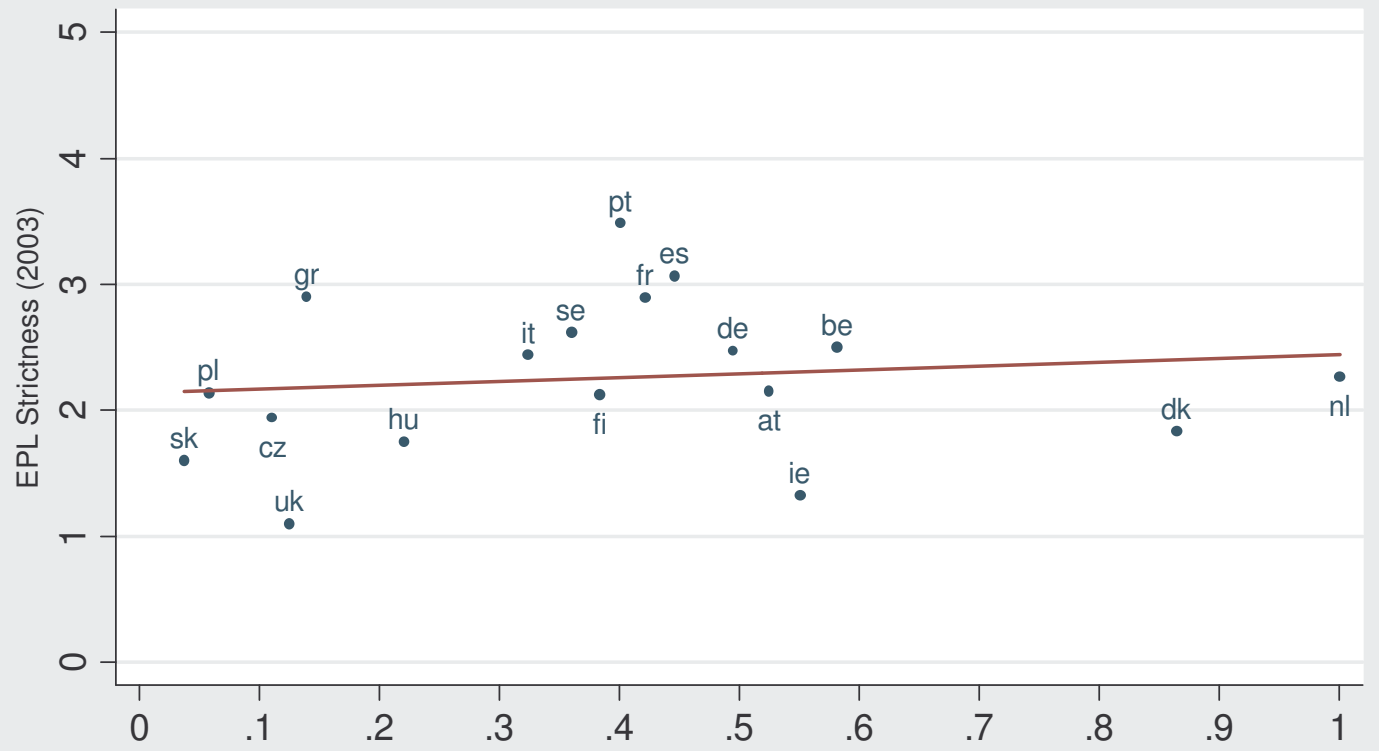

Expenditure on out-of-work income maintenance and support per unemployed relative to YPC (2005) Data not available for bg, cy, ee, Iv, It, lu, mt, ro and si 
Figure 4

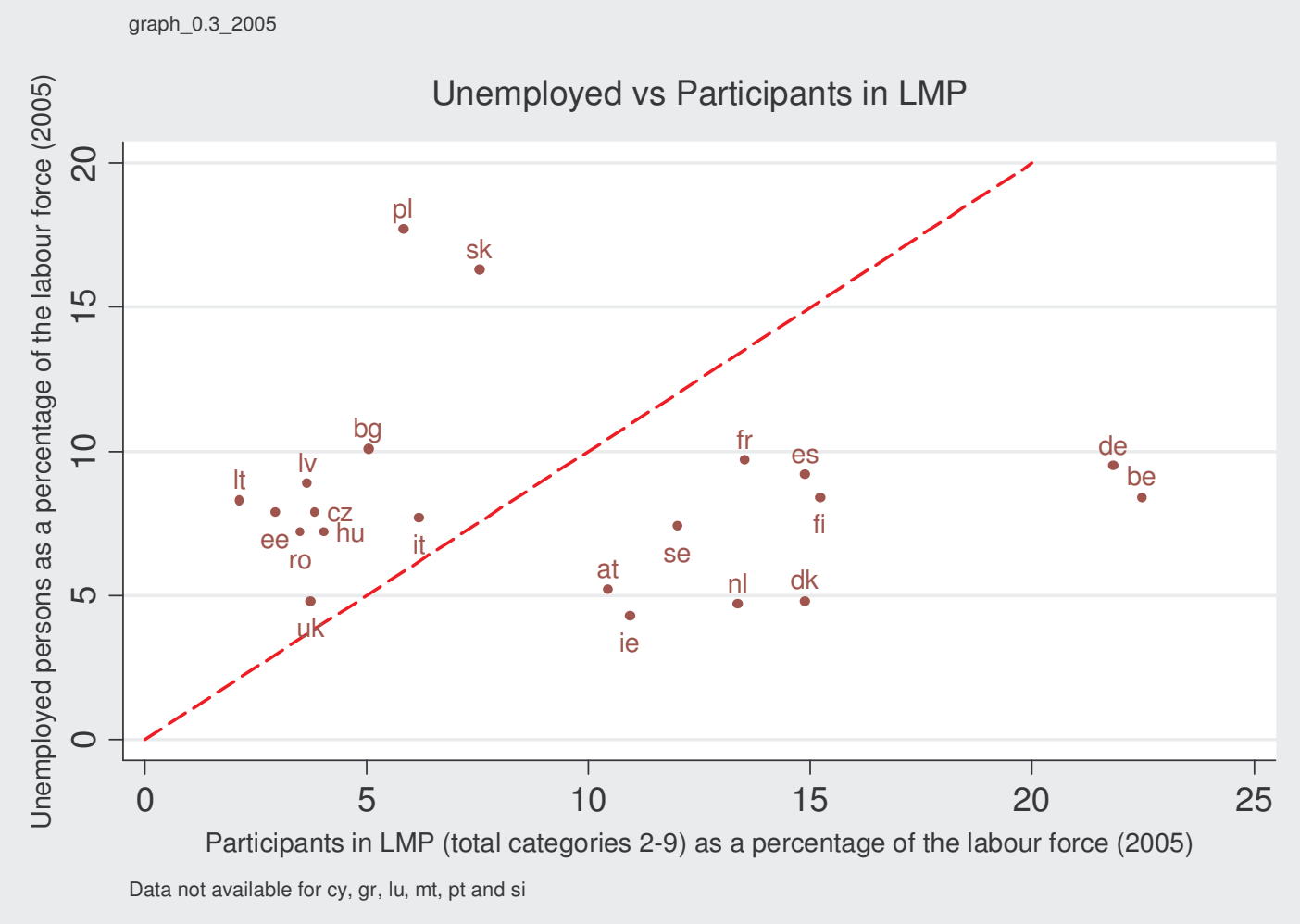

\section{Figure 5}

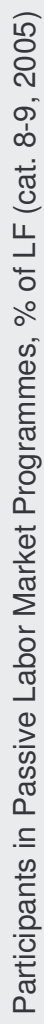

graph_0.4_2005

Participants in LM Programs

ㅇ-

10

$+$

de
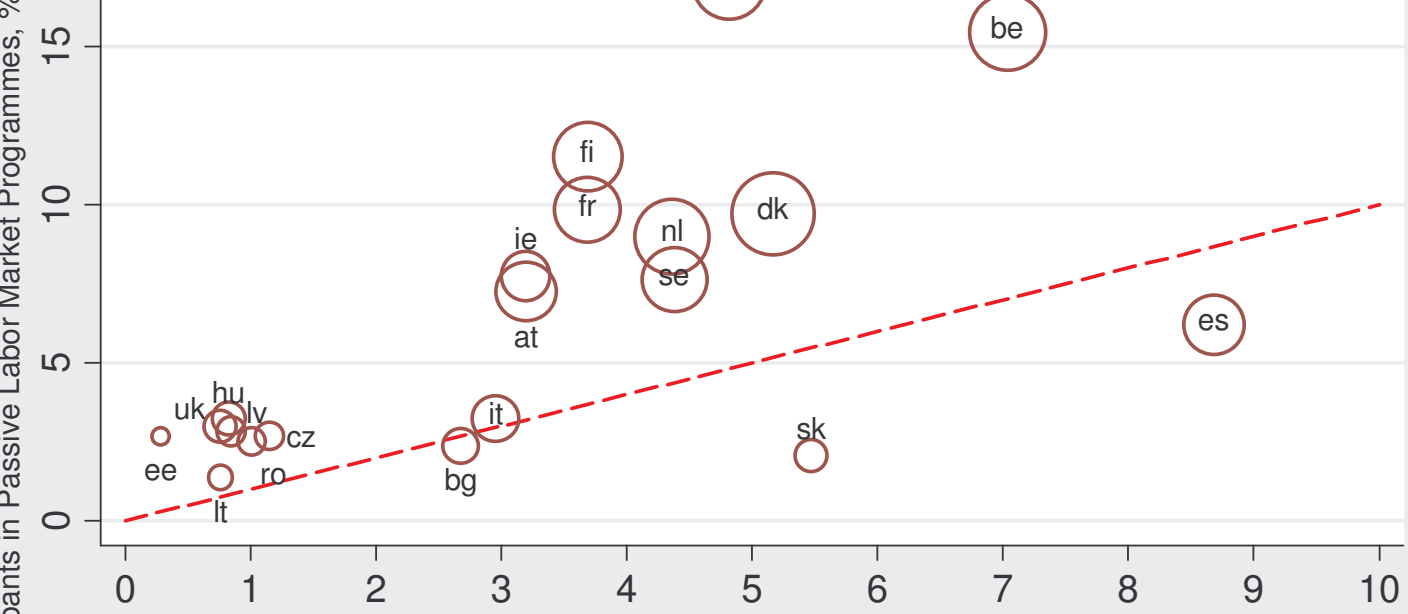

Participants in Active Labor Market Programmes, \% of LF (cat. 2-7, 2005)

Data not available for cy, gr, lu, mt, pl, pt and si

Area of symbol proportional to public expenditure in LMP as percentage of GDP 
Figure 6

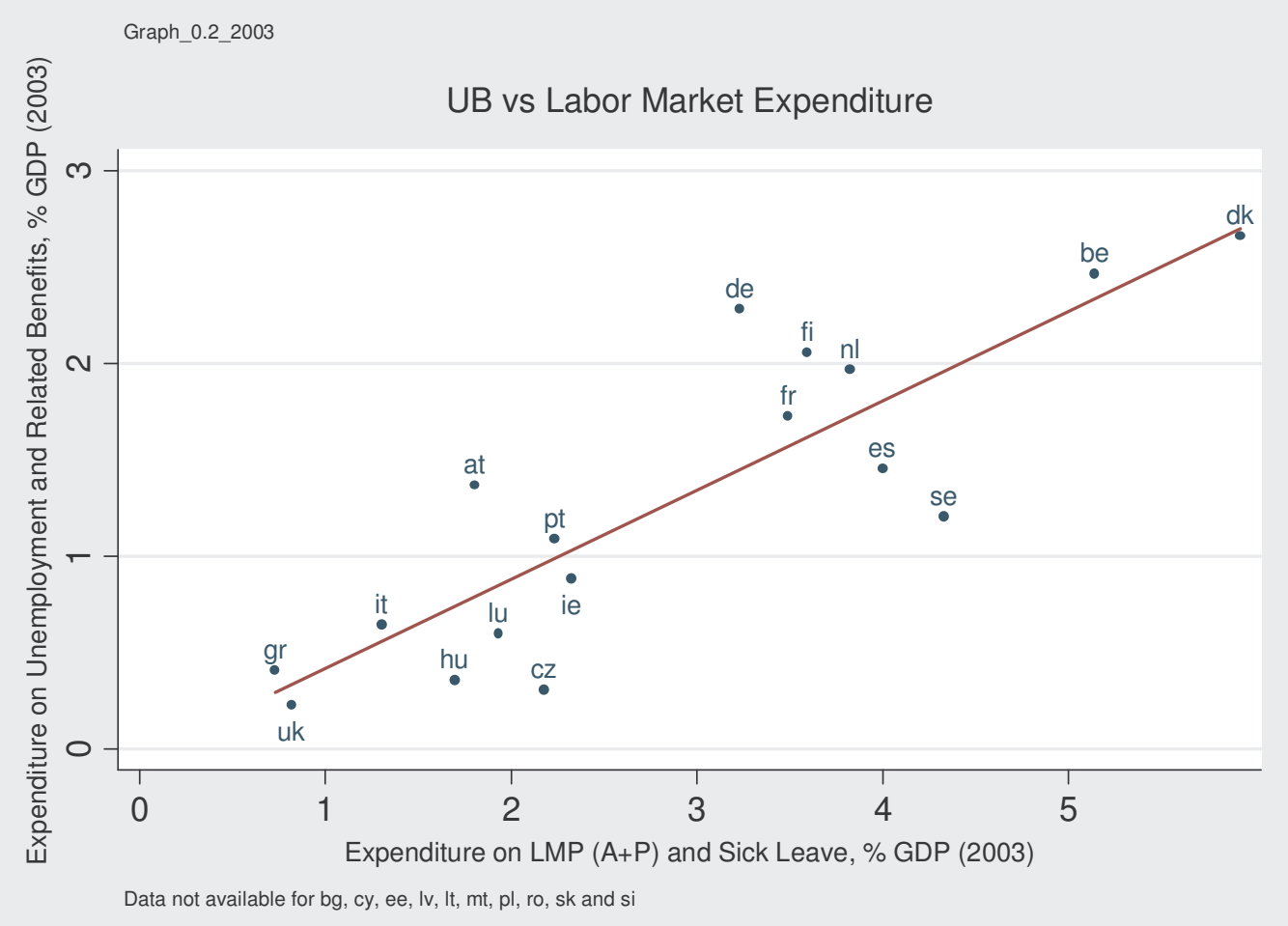

Figure 7.a

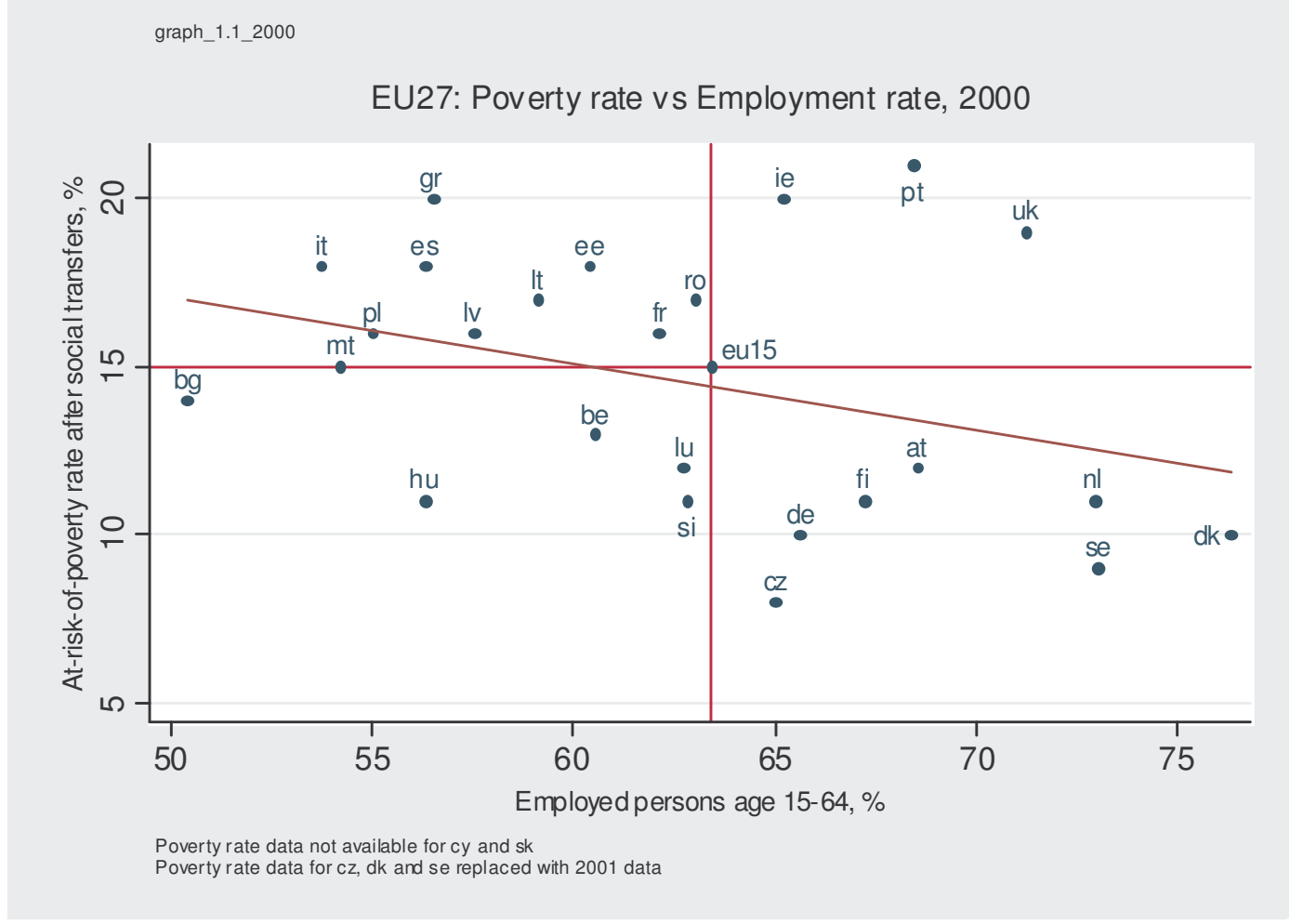


Figure 7.b

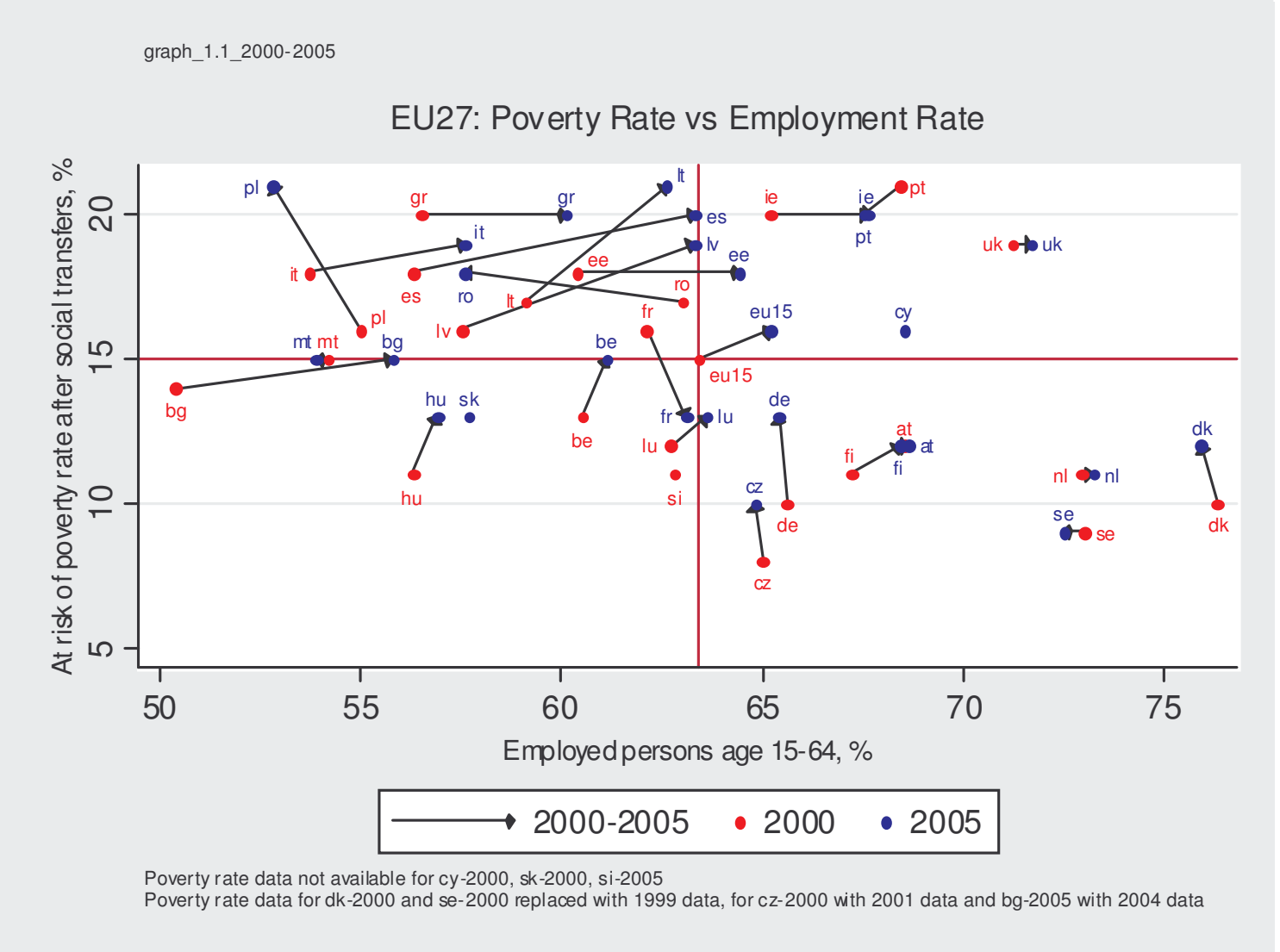

Figure 8

graph_3.3_2005

Poverty risk vs Labor Market Expenditure (\% GDP)

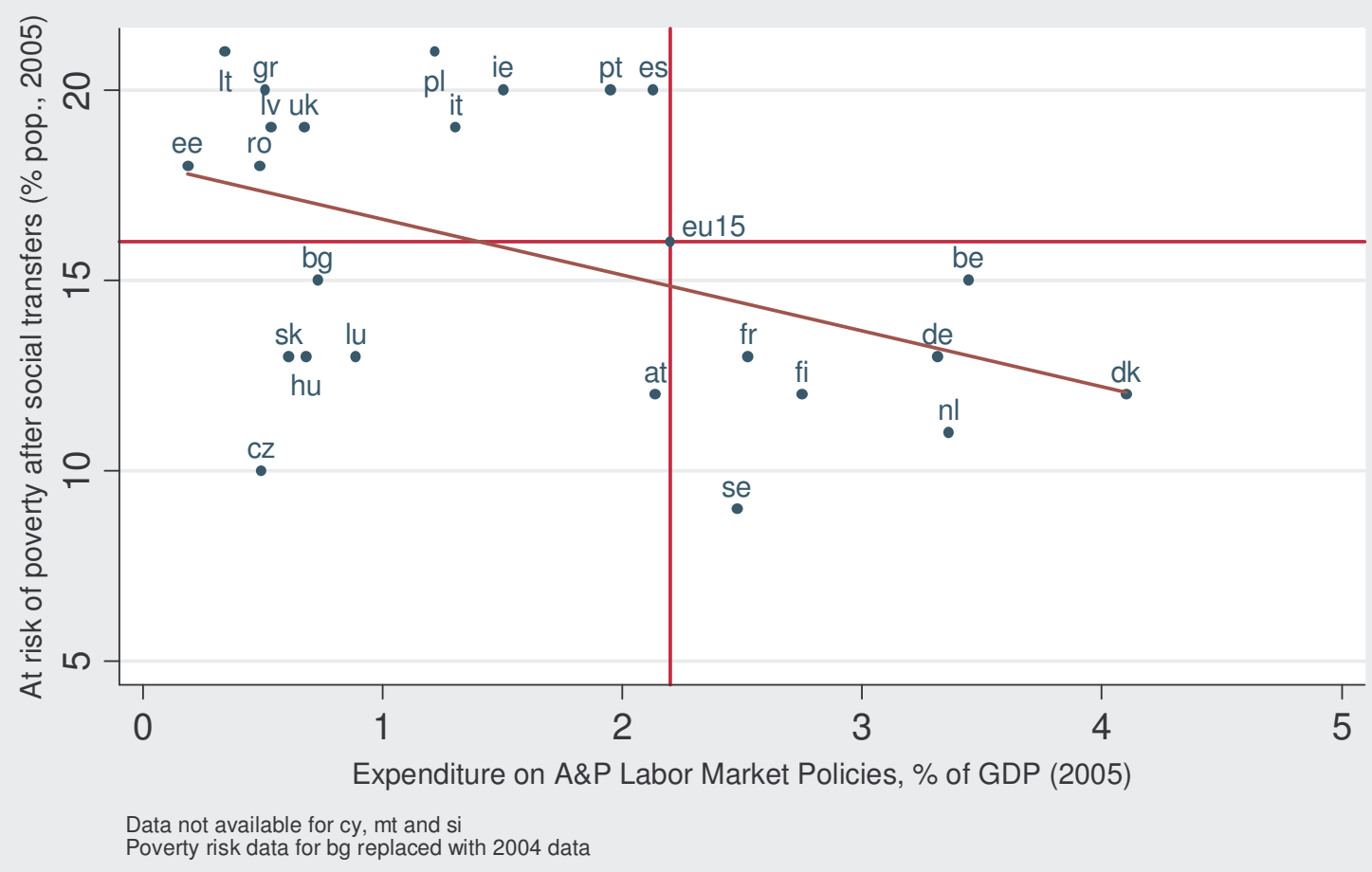


Figure 9

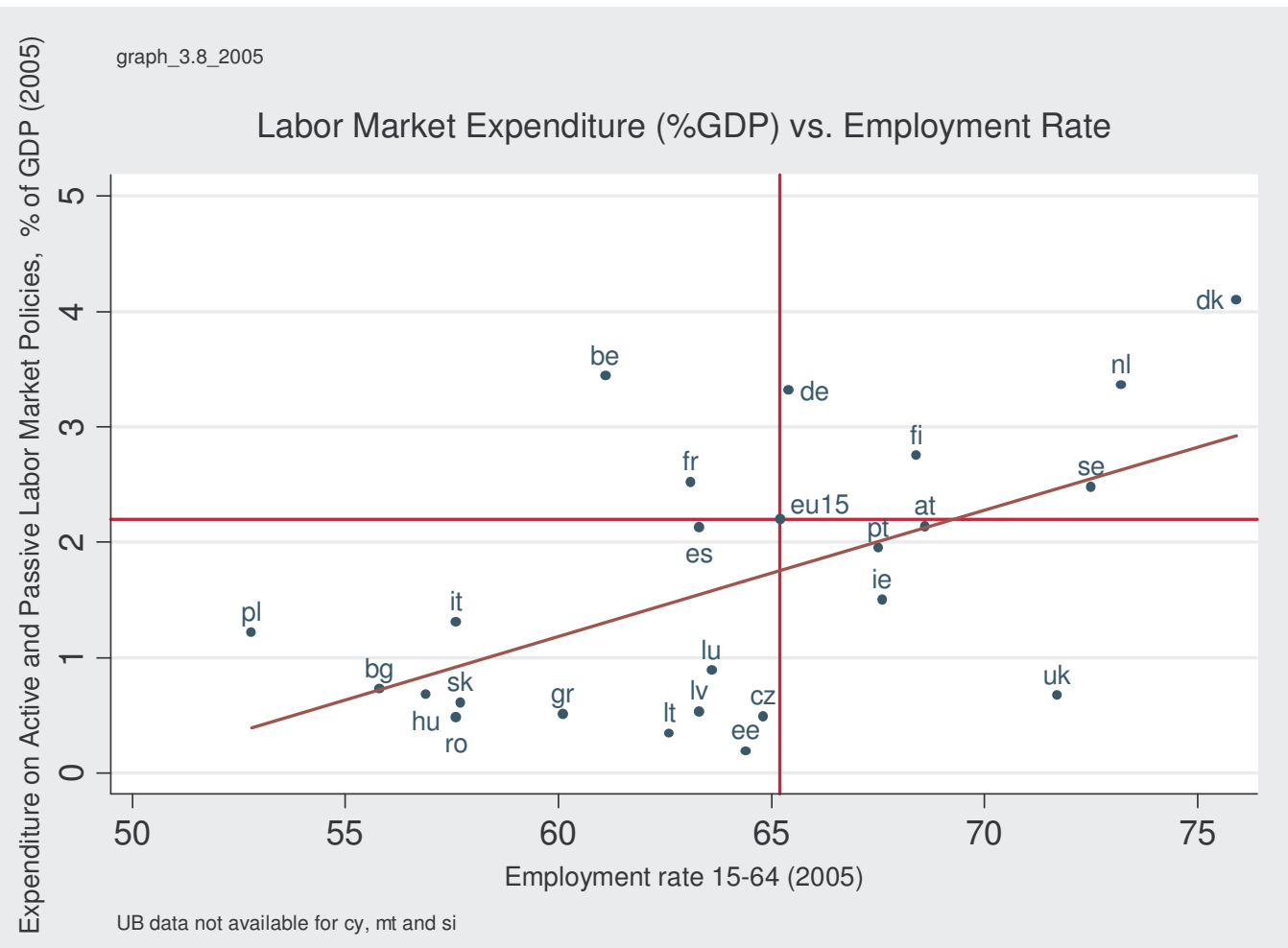

Figure 10

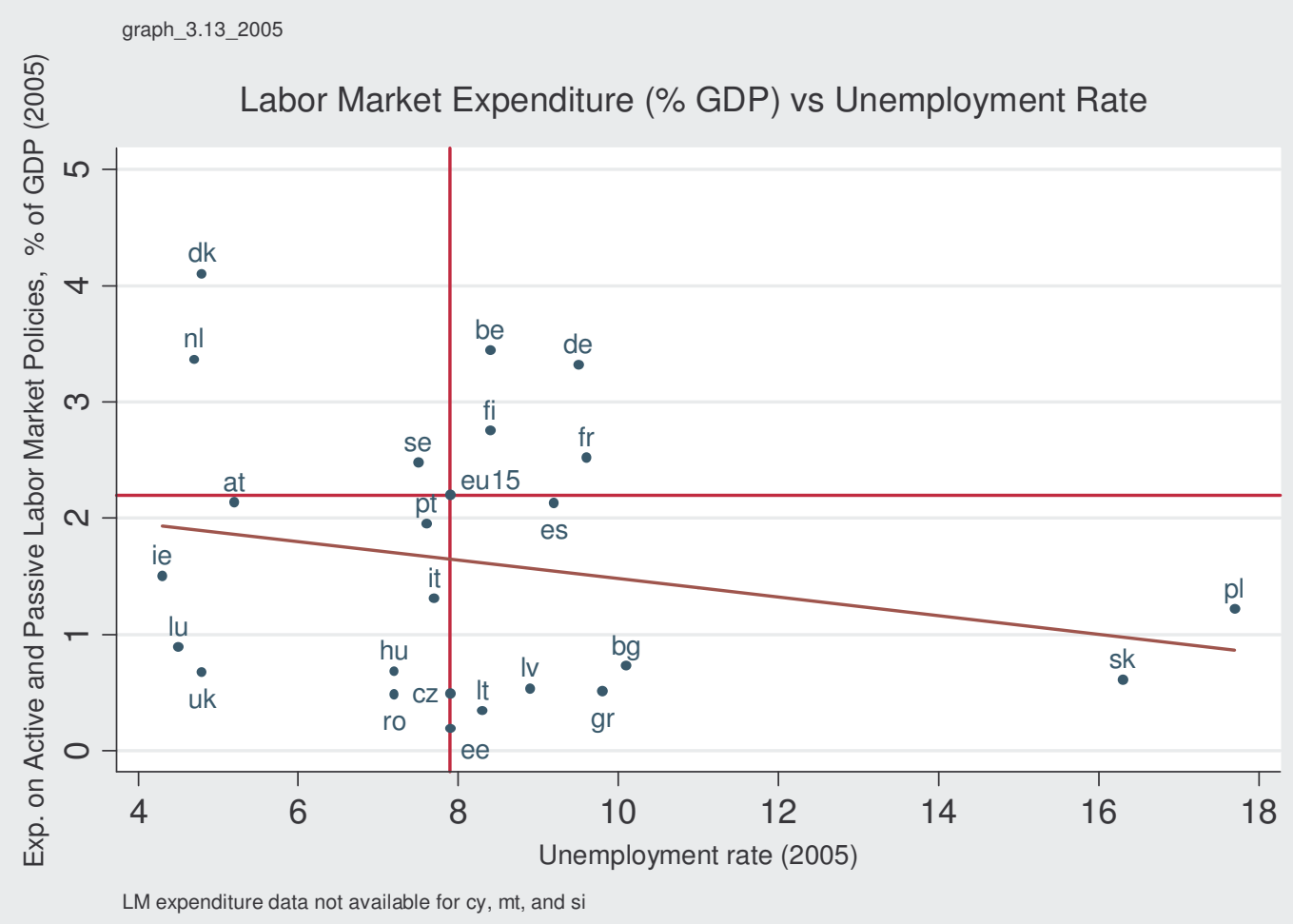


Figure 11

graph_3.10_2005

Union Protection Index vs Employment rate

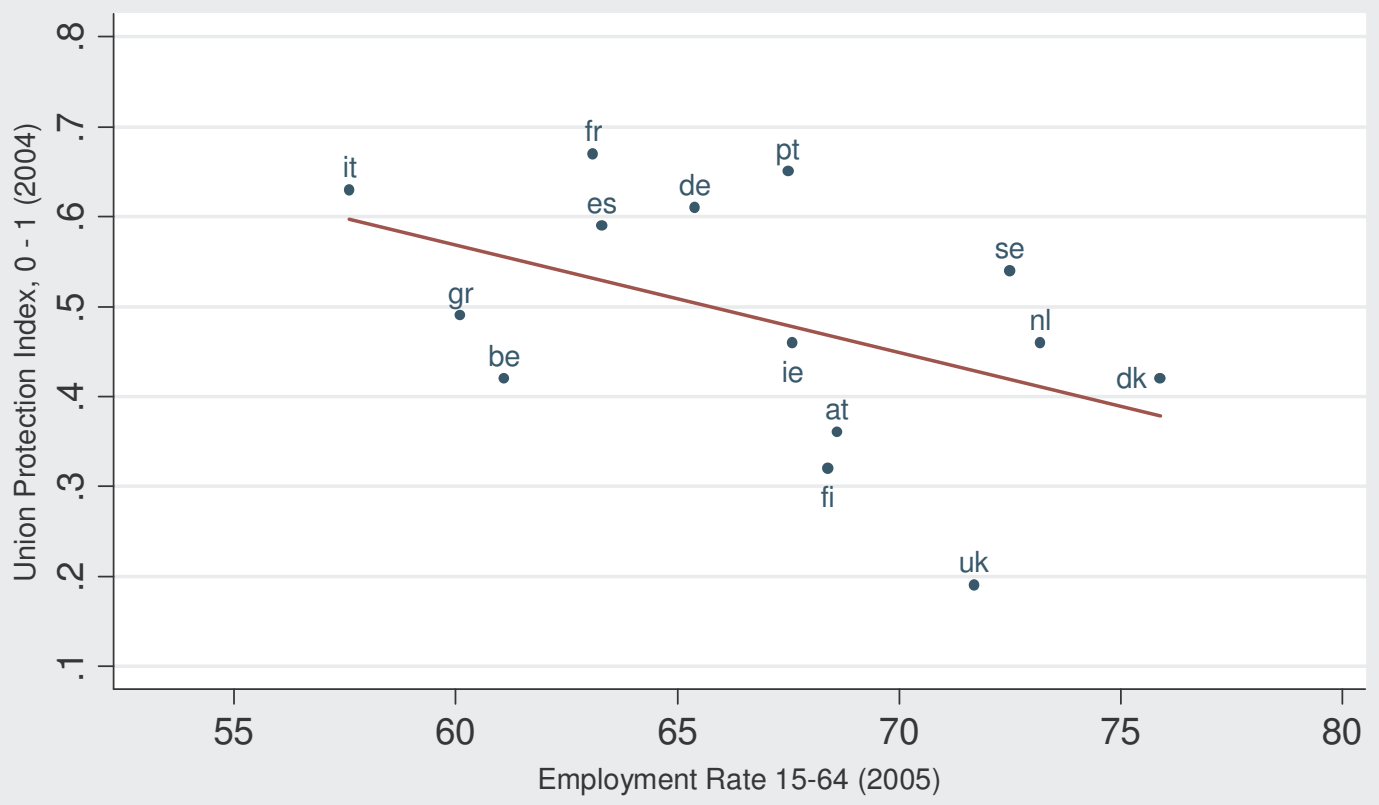

Union Protection Index data not available for bg, cy, cz, ee, hu, It, lv, lu, mt, pl, ro, sk and si

Figure 12

graph_3.9_2005

EPL vs Employment Rate

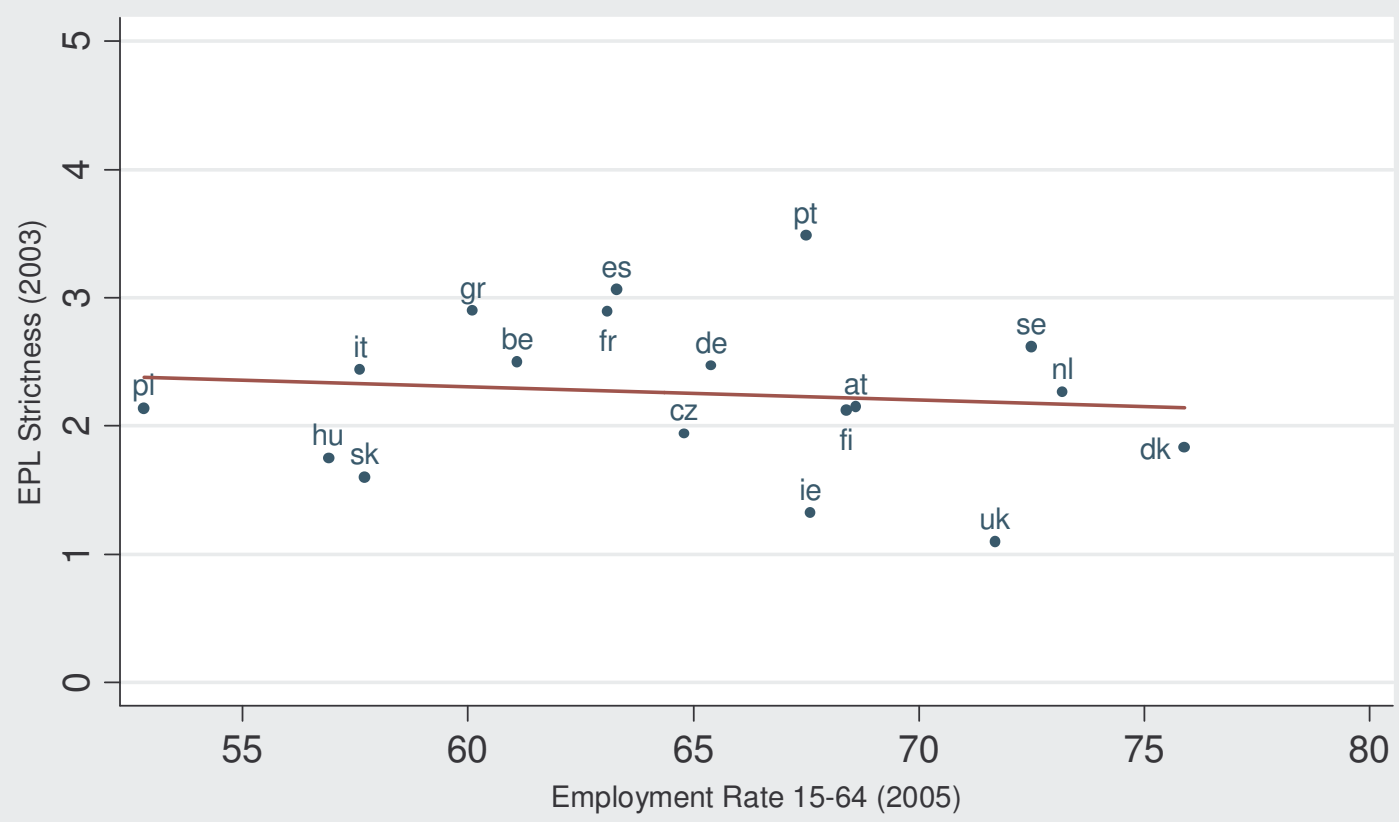

EPL Strictness data not available for bg, cy, ee, It, Iv, lu, mt, ro and si 
Figure 13

graph_3.15_2005

Union Protection Index vs Unemployment Rate

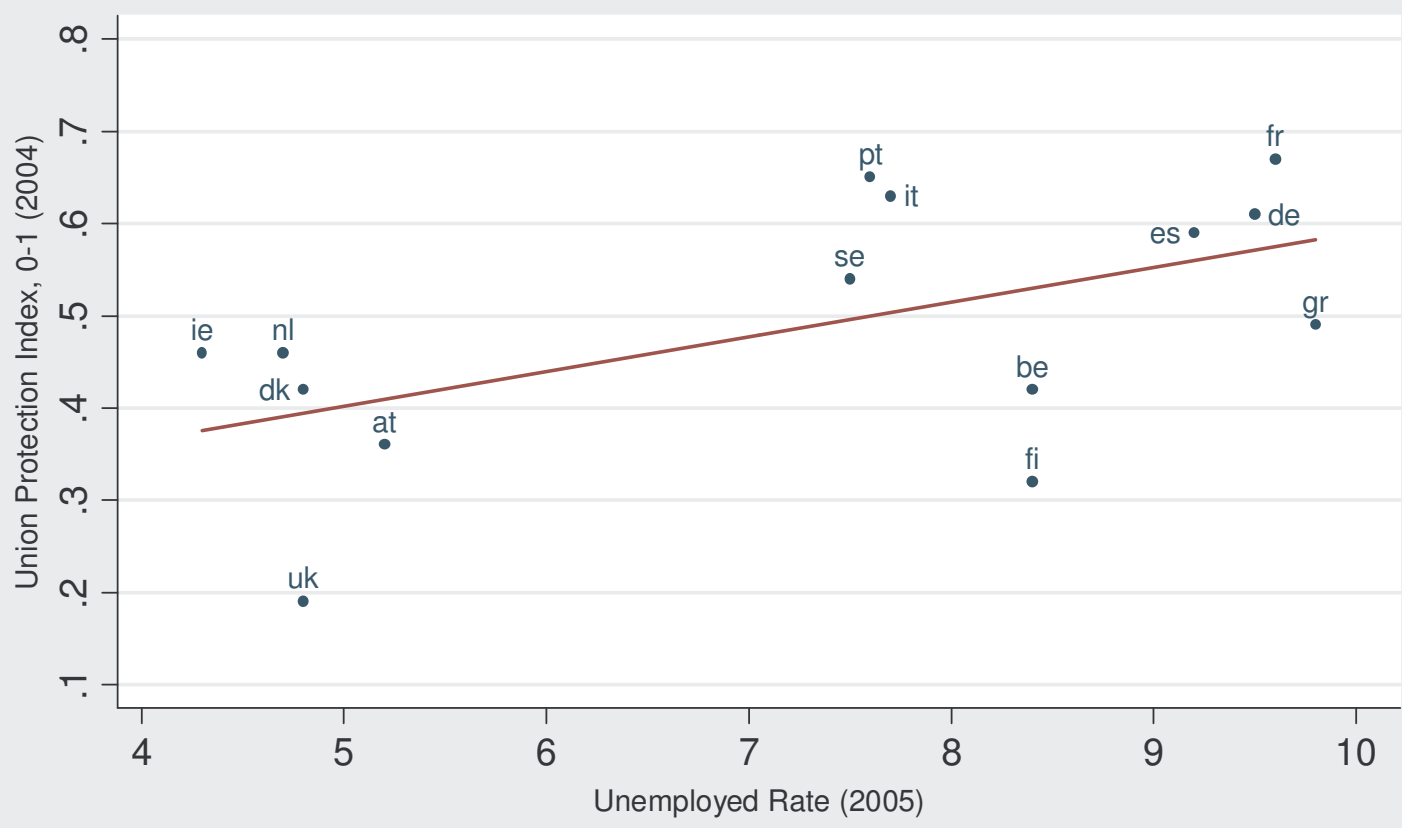

Union Protection Index data not available for bg, cy, cz, ee, hu, It, lv, lu, mt, pl, ro, sk and si

Figure 14

graph_3.14_2000

EPL vs Unemployment Rate

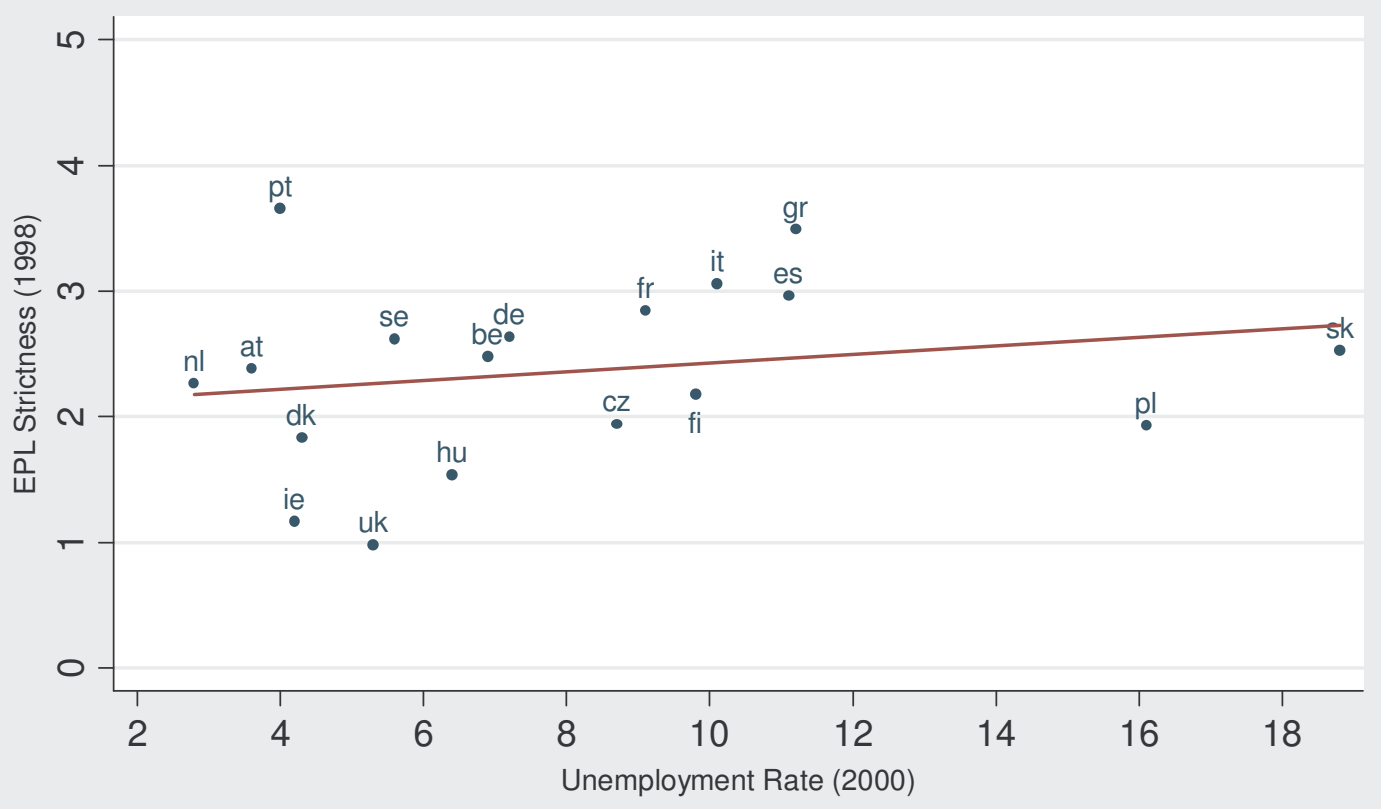

EPL Strictness data not available for bg, cy, ee, It, lv, lu, mt, ro and si 
Figure 15

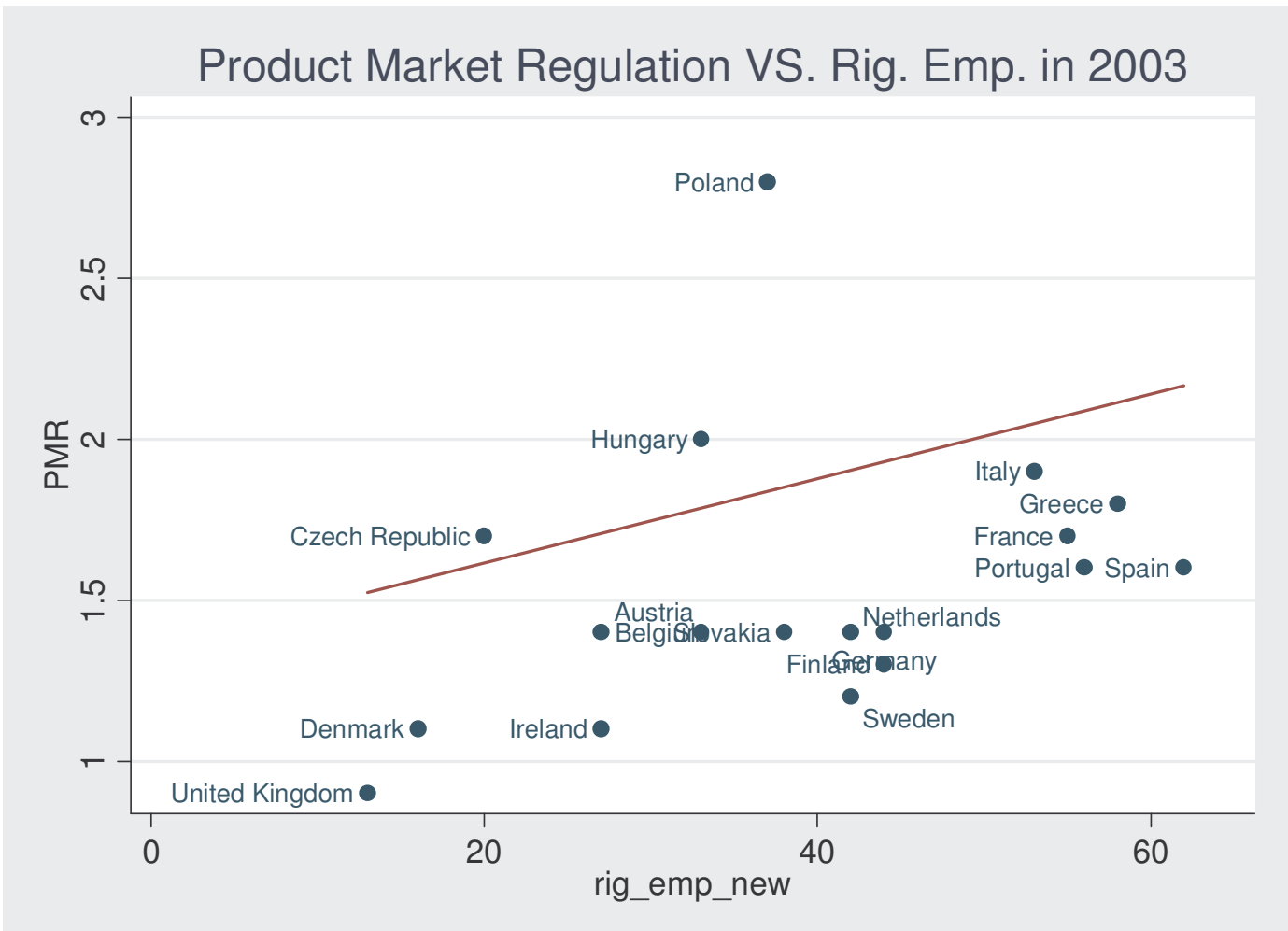

Figure 16

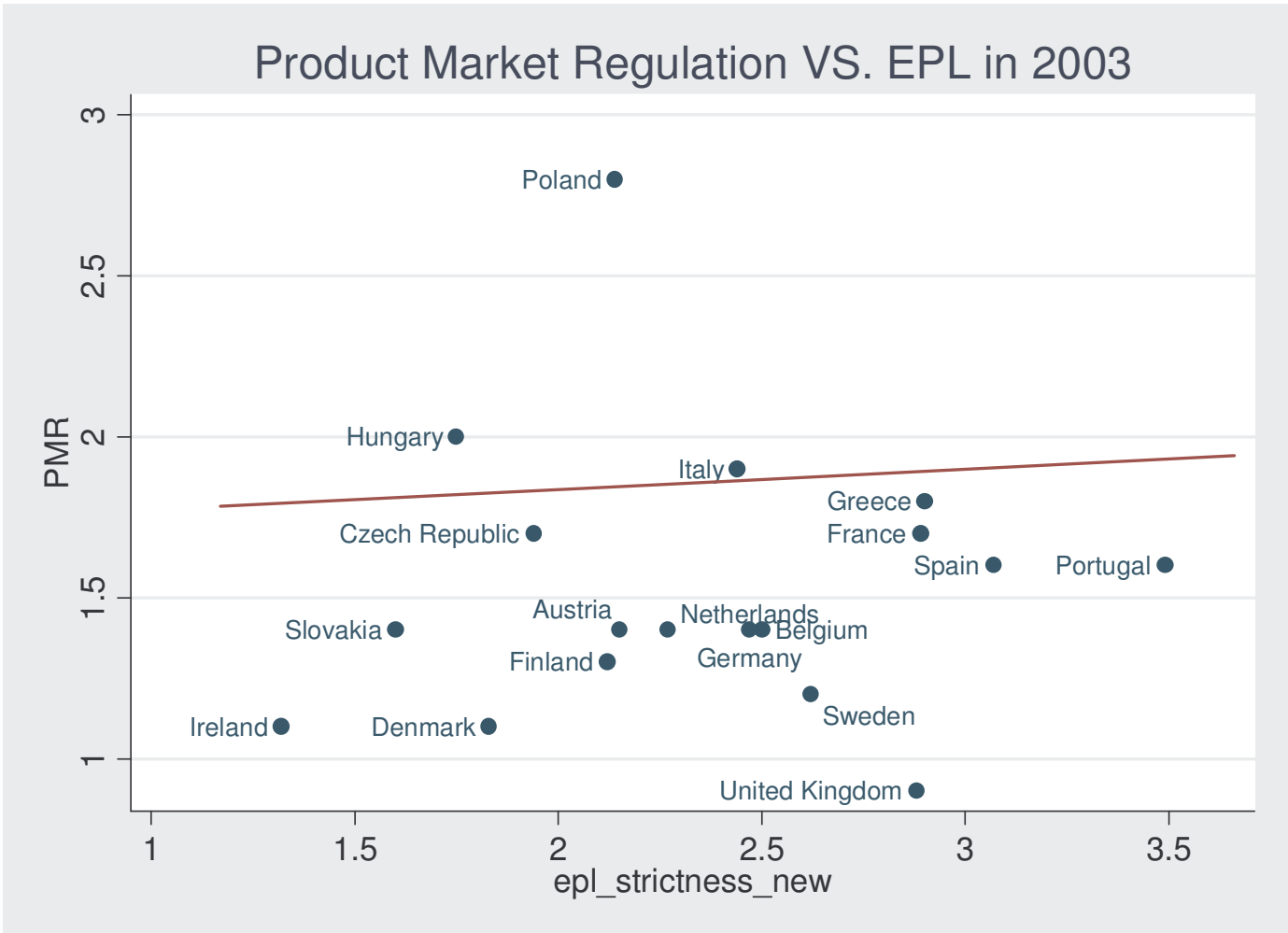


Table 1 - Labor market programmes and EPL strictness

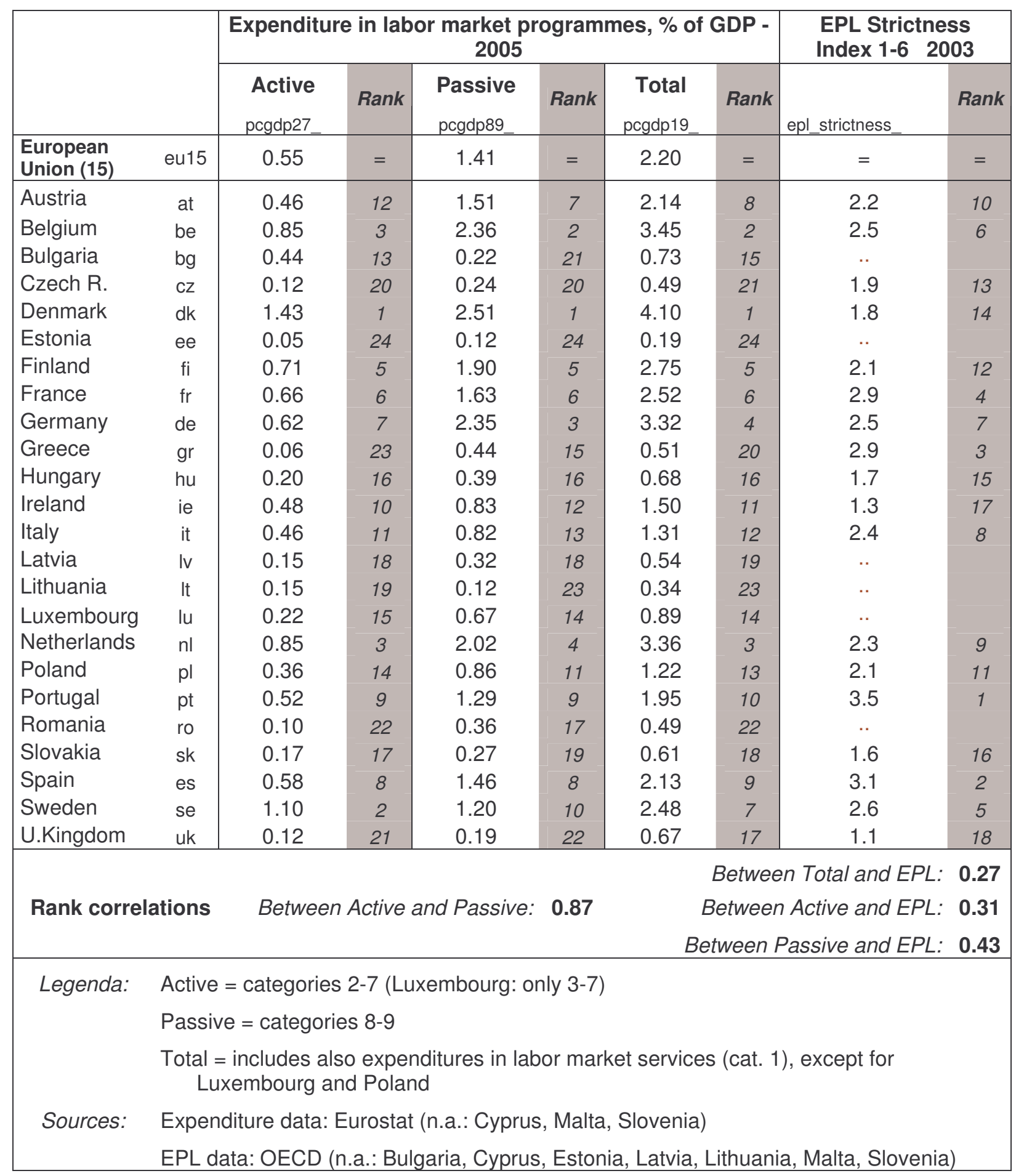


Table 2. Not yet an Anglo-Nordic model

\begin{tabular}{|l|l|l|l|}
\hline & DK & SE & UK-IE \\
\hline Net Replacement rates & $\mathrm{Hi}$ & $\mathrm{Hi}$ & Lo \\
\hline Tax Wedge (cost of LM policies) & $\mathrm{Hi}$ & $\mathrm{Hi}$ & Lo \\
\hline EPL & $\mathrm{LO}$ & $\mathrm{HI}$ & $\mathrm{Lo}$ \\
\hline UB duration & $\mathrm{Hi}$ & $\mathrm{Me}-\mathrm{Hi}$ & $\mathrm{Me}$ \\
\hline Spending on ALMP & $\mathrm{Hi}$ & $\mathrm{Me}-\mathrm{Hi}$ & Lo \\
\hline
\end{tabular}

Source: Information provided in Zhou (2007). 
Table 3.1. Employment Rate; Explanatory Variables Rigidity of Employment and LMP

\begin{tabular}{|c|c|c|c|c|c|c|c|c|c|c|}
\hline & \multicolumn{5}{|c|}{ Average $2000-2005$} & \multicolumn{5}{|c|}{ Pooled 2000-02 \& 2003-05 } \\
\hline & (1) & $(2)$ & (3) & $(4)$ & (5) & (6) & (7) & $(8)$ & $(9)$ & $(10)$ \\
\hline & Em.Rate & Em.Rate & Em.Rate & Em.Rate & Em.Rate & Em.Rate & Em.Rate & Em.Rate & Em.Rate & Em.Rate \\
\hline \multirow[t]{2}{*}{ Rig_Emp } & -0.135 & -0.117 & -0.129 & $-0.165^{*}$ & $-0.149 *$ & $-0.165 * * *$ & $-0.149 * *$ & $-0.160 * * *$ & $-0.190 * * *$ & $-0.175^{* * *}$ \\
\hline & $(0.083)$ & $(0.082)$ & $(0.082)$ & $(0.079)$ & $(0.084)$ & $(0.060)$ & $(0.058)$ & $(0.059)$ & $(0.059)$ & $(0.061)$ \\
\hline \multirow[t]{2}{*}{ Sum_LMP_1-9 } & $2.763 * *$ & & & & & $2.279 * * *$ & & & & \\
\hline & $(1.033)$ & & & & & $(0.761)$ & & & & \\
\hline \multirow[t]{2}{*}{ Sum_LMP_1-7 } & & $8.075^{* * *}$ & & & & & $7.008 * * *$ & & & \\
\hline & & $(2.771)$ & & & & & $(1.979)$ & & & \\
\hline \multirow[t]{2}{*}{ Sum_LMP_2-7 } & & & $7.865 * *$ & & & & & $6.822 * * *$ & & \\
\hline & & & $(2.876)$ & & & & & $(2.127)$ & & \\
\hline \multirow[t]{2}{*}{ LMP_8 } & & & & $4.895^{* *}$ & & & & & $3.856 * * *$ & \\
\hline & & & & $(1.743)$ & & & & & $(1.319)$ & \\
\hline \multirow[t]{2}{*}{ Sum_LMP_8-9 } & & & & & $3.771^{* *}$ & & & & & $2.943 * *$ \\
\hline & & & & & $(1.587)$ & & & & & $(1.172)$ \\
\hline Observations & 23 & 23 & 23 & 23 & 23 & 38 & 38 & 38 & 38 & 38 \\
\hline Adj. R-squared & 0.33 & 0.36 & 0.34 & 0.35 & 0.29 & 0.34 & 0.39 & 0.36 & 0.33 & 0.29 \\
\hline
\end{tabular}

Standard errors in parentheses. * denotes significant at $10 \% ; * *$ significant at $5 \%$; ** significant at $1 \%$.

Constant and also time dummies for the Pooled equations (col. 6-10) are not reported. 
Table 3.2. Unemployment Rate. Explanatory Variables, Rigidity of Employment and LMP

\begin{tabular}{|c|c|c|c|c|c|c|c|c|c|c|}
\hline & \multicolumn{5}{|c|}{ Average $2000-2005$} & \multicolumn{5}{|c|}{ Pooled 2000-02 \& 2003-05 } \\
\hline & $(1)$ & $(2)$ & $(3)$ & $(4)$ & $(5)$ & $(6)$ & $(7)$ & $(8)$ & $(9)$ & $(10)$ \\
\hline & Un. Rate & Un. Rate & Un. Rate & Un. Rate & Un. Rate & Un. Rate & Un. Rate & Un. Rate & Un. Rate & Un. Rate \\
\hline \multirow[t]{2}{*}{ Rig_Emp } & 0.062 & 0.055 & 0.060 & 0.074 & 0.068 & $0.069 *$ & $0.063 *$ & $0.067 *$ & $0.076 * *$ & $0.072 * *$ \\
\hline & $(0.058)$ & $(0.059)$ & $(0.059)$ & $(0.055)$ & $(0.058)$ & $(0.035)$ & $(0.035)$ & $(0.035)$ & $(0.034)$ & $(0.035)$ \\
\hline \multirow[t]{2}{*}{ Sum_LMP_1-9 } & $-1.312 *$ & & & & & -0.679 & & & & \\
\hline & $(0.731)$ & & & & & $(0.450)$ & & & & \\
\hline \multirow[t]{2}{*}{ Sum_LMP_1-7 } & & $-3.670 *$ & & & & & $-2.259 *$ & & & \\
\hline & & $(2.003)$ & & & & & $(1.197)$ & & & \\
\hline \multirow[t]{2}{*}{ Sum_LMP_2-7 } & & & $-3.593 *$ & & & & & -2.076 & & \\
\hline & & & $(2.055)$ & & & & & $(1.270)$ & & \\
\hline \multirow[t]{2}{*}{ LMP_8 } & & & & $-2.730 * *$ & & & & & $-1.386 *$ & \\
\hline & & & & $(1.201)$ & & & & & $(0.765)$ & \\
\hline \multirow[t]{2}{*}{ Sum_LMP_8-9 } & & & & & -1.840 & & & & & -0.825 \\
\hline & & & & & $(1.102)$ & & & & & $(0.679)$ \\
\hline Observations & 23 & 23 & 23 & 23 & 23 & 38 & 38 & 38 & 38 & 38 \\
\hline $\begin{array}{l}\text { Adjusted R- } \\
\text { squared }\end{array}$ & 0.14 & 0.15 & 0.14 & 0.21 & 0.12 & 0.18 & 0.21 & 0.19 & 0.20 & 0.16 \\
\hline
\end{tabular}


Table 3.3. Activity Rate. Explanatory Variables, Rigidity of Employment and LMP

\begin{tabular}{|c|c|c|c|c|c|c|c|c|c|c|}
\hline & \multicolumn{5}{|c|}{ Average 2000-2005 } & \multicolumn{5}{|c|}{ Pooled 2000-02 \& 2003-05 } \\
\hline & $(1)$ & $(2)$ & (3) & $(4)$ & $(5)$ & $(6)$ & $(7)$ & $(8)$ & $(9)$ & $(10)$ \\
\hline & Act.Rate & Act.Rate & Act.Rate & Act.Rate & Act. Rate & Act.Rate & Act.Rate & Act.Rate & Act.Rate & Act. Rate \\
\hline \multirow[t]{2}{*}{ Rig_Emp } & -0.091 & -0.078 & -0.087 & -0.115 & -0.102 & $-0.120 * *$ & $-0.107^{* *}$ & $-0.117^{* *}$ & $-0.142 * * *$ & $-0.128 * *$ \\
\hline & $(0.069)$ & $(0.069)$ & $(0.069)$ & $(0.068)$ & $(0.070)$ & $(0.051)$ & $(0.050)$ & $(0.050)$ & $(0.051)$ & $(0.052)$ \\
\hline \multirow[t]{2}{*}{ Sum_LMP_1-9 } & $2.010 * *$ & & & & & $1.971 * * *$ & & & & \\
\hline & $(0.864)$ & & & & & $(0.650)$ & & & & \\
\hline \multirow[t]{2}{*}{ Sum_LMP_1-7 } & & $5.923 * *$ & & & & & $5.849 * * *$ & & & \\
\hline & & $(2.324)$ & & & & & $(1.709)$ & & & \\
\hline \multirow[t]{2}{*}{ Sum_LMP_2-7 } & & & $5.756 * *$ & & & & & $5.779 * * *$ & & \\
\hline & & & $(2.404)$ & & & & & $(1.826)$ & & \\
\hline \multirow[t]{2}{*}{ LMP_8 } & & & & $3.308^{* *}$ & & & & & $3.211 * * *$ & \\
\hline & & & & $(1.491)$ & & & & & $(1.136)$ & \\
\hline \multirow[t]{2}{*}{ Sum_LMP_8-9 } & & & & & $2.728^{*}$ & & & & & $2.608^{* *}$ \\
\hline & & & & & $(1.319)$ & & & & & $(0.997)$ \\
\hline Observations & 23 & 23 & 23 & 23 & 23 & 38 & 38 & 38 & 38 & 38 \\
\hline $\begin{array}{l}\text { Adjusted R- } \\
\text { squared }\end{array}$ & 0.25 & 0.28 & 0.26 & 0.23 & 0.21 & 0.29 & 0.33 & 0.30 & 0.27 & 0.25 \\
\hline
\end{tabular}


Table 4.1. Employment Rate. Explanatory Variables: EPL and LMP

\begin{tabular}{|c|c|c|c|c|c|c|c|c|c|c|}
\hline & \multicolumn{5}{|c|}{ Average 2000-2005 } & \multicolumn{5}{|c|}{ Pooled 2000-02 \& 2003-05 } \\
\hline & $(1)$ & $(2)$ & (3) & $(4)$ & $(5)$ & $(6)$ & $(7)$ & $(8)$ & (9) & $(10)$ \\
\hline \multirow[t]{2}{*}{ EPL_Strict } & 0.730 & 1.074 & 0.954 & 0.144 & 0.625 & -0.180 & 0.270 & 0.209 & -0.767 & -0.407 \\
\hline & $(2.637)$ & $(2.405)$ & $(2.509)$ & $(2.762)$ & $(2.787)$ & $(1.911)$ & $(1.786)$ & $(1.859)$ & $(1.982)$ & $(1.992)$ \\
\hline Sum_LMP_1-9 & $(1.337)$ & & & & & $(0.957)$ & & & & \\
\hline \multirow[t]{2}{*}{ Sum_LMP_1-7 } & & $10.024 * * *$ & & & & & $8.573 * * *$ & & & \\
\hline & & $(3.265)$ & & & & & $(2.369)$ & & & \\
\hline \multirow[t]{2}{*}{ Sum_LMP_2-7 } & & & $9.444^{* *}$ & & & & & $8.048 * * *$ & & \\
\hline & & & $(3.464)$ & & & & & $(2.555)$ & & \\
\hline \multirow[t]{2}{*}{ Sum_LMP_8-9 } & & & & & $3.836 *$ & & & & & $3.126 * *$ \\
\hline & & & & & $(2.128)$ & & & & & $(1.498)$ \\
\hline Observations & 18 & 18 & 18 & 18 & 18 & 33 & 33 & 33 & 33 & 33 \\
\hline $\begin{array}{l}\text { Adjusted R- } \\
\text { squared }\end{array}$ & 0.17 & 0.31 & 0.25 & 0.11 & 0.07 & 0.13 & 0.25 & 0.19 & 0.06 & 0.05 \\
\hline
\end{tabular}


Table 4.2. Unemployment Rate; Explanatory Variables, Employment Protection Legislation and LMP

\begin{tabular}{|c|c|c|c|c|c|c|c|c|c|c|}
\hline & \multicolumn{5}{|c|}{ Average $2000-2005$} & \multicolumn{5}{|c|}{ Pooled 2000-02 \& 2003-05 } \\
\hline & $(1)$ & $(2)$ & $(3)$ & $(4)$ & $(5)$ & $(6)$ & $(7)$ & $(8)$ & (9) & $(10)$ \\
\hline & Un. Rate & Un. Rate & Un. Rate & Un. Rate & Un. Rate & Un. Rate & Un. Rate & Un. Rate & Un. Rate & Un. Rate \\
\hline \multirow[t]{2}{*}{ EPL_Strict } & -0.669 & -0.810 & -0.759 & -0.370 & -0.631 & 0.220 & 0.053 & 0.090 & 0.413 & 0.295 \\
\hline & $(1.794)$ & $(1.725)$ & $(1.753)$ & $(1.796)$ & $(1.837)$ & $(1.096)$ & $(1.066)$ & $(1.088)$ & $(1.097)$ & $(1.113)$ \\
\hline \multirow[t]{2}{*}{ Sum_LMP_1-9 } & -1.238 & & & & & -0.805 & & & & \\
\hline & $(0.910)$ & & & & & $(0.549)$ & & & & \\
\hline \multirow[t]{2}{*}{ Sum_LMP_1-7 } & & $-4.193 *$ & & & & & $-2.938 * *$ & & & \\
\hline & & $(2.342)$ & & & & & $(1.413)$ & & & \\
\hline \multirow[t]{2}{*}{ Sum_LMP_2-7 } & & & -3.929 & & & & & $-2.592 *$ & & \\
\hline & & & $(2.419)$ & & & & & $(1.496)$ & & \\
\hline \multirow[t]{2}{*}{ LMP_8 } & & & & -2.313 & & & & & -1.360 & \\
\hline & & & & $(1.575)$ & & & & & $(0.958)$ & \\
\hline \multirow[t]{2}{*}{ Sum_LMP_8-9 } & & & & & -1.482 & & & & & -0.875 \\
\hline & & & & & $(1.402)$ & & & & & $(0.837)$ \\
\hline Observations & 18 & 18 & 18 & 18 & 18 & 33 & 33 & 33 & 33 & 33 \\
\hline $\begin{array}{l}\text { Adjusted R- } \\
\text { squared }\end{array}$ & 0.00 & 0.08 & 0.05 & 0.02 & -0.04 & 0.04 & 0.10 & 0.06 & 0.03 & 0.00 \\
\hline
\end{tabular}


Table 4.3. Activity Rate; Explanatory Variables, Employment Protection Legislation and LMP

\begin{tabular}{|c|c|c|c|c|c|c|c|c|c|c|}
\hline & \multicolumn{5}{|c|}{ Average 2000-2005 } & \multicolumn{5}{|c|}{ Pooled 2000-02 \& 2003-05 } \\
\hline & $(1)$ & $(2)$ & (3) & $(4)$ & $(5)$ & $(6)$ & $(7)$ & $(8)$ & $(9)$ & $(10)$ \\
\hline & Act.Rate & Act.Rate & Act.Rate & Act.Rate & Act.Rate & Act.Rate & Act.Rate & Act.Rate & Act. Rate & Act. Rate \\
\hline \multirow[t]{2}{*}{ EPL_Strict } & 0.377 & 0.644 & 0.552 & -0.046 & 0.290 & 0.070 & 0.427 & 0.388 & -0.427 & -0.118 \\
\hline & $(2.133)$ & $(1.986)$ & $(2.057)$ & $(2.260)$ & $(2.238)$ & $(1.556)$ & $(1.473)$ & $(1.522)$ & $(1.627)$ & $(1.620)$ \\
\hline \multirow[t]{2}{*}{ Sum_LMP_1-9 } & $2.420 * *$ & & & & & $2.226 * * *$ & & & & \\
\hline & $(1.082)$ & & & & & $(0.780)$ & & & & \\
\hline \multirow[t]{2}{*}{ Sum_LMP_1-7 } & & $7.658 * *$ & & & & & $7.024 * * *$ & & & \\
\hline & & $(2.695)$ & & & & & $(1.953)$ & & & \\
\hline \multirow[t]{2}{*}{ Sum_LMP_2-7 } & & & $7.234 * *$ & & & & & $6.719 * * *$ & & \\
\hline & & & $(2.839)$ & & & & & $(2.092)$ & & \\
\hline \multirow[t]{2}{*}{ LMP_8 } & & & & $3.529 *$ & & & & & $3.139 * *$ & \\
\hline & & & & $(1.982)$ & & & & & $(1.421)$ & \\
\hline \multirow[t]{2}{*}{ Sum_LMP_8-9 } & & & & & $3.068^{*}$ & & & & & $2.768^{* *}$ \\
\hline & & & & & $(1.708)$ & & & & & $(1.218)$ \\
\hline Observations & 18 & 18 & 18 & 18 & 18 & 33 & 33 & 33 & 33 & 33 \\
\hline $\begin{array}{l}\text { Adjusted R- } \\
\text { squared }\end{array}$ & 0.15 & 0.27 & 0.21 & 0.07 & 0.07 & 0.14 & 0.24 & 0.19 & 0.06 & 0.06 \\
\hline
\end{tabular}


Table 5.1. Employment Rate; Explanatory Variables:Product Market Legislation and LMP

\begin{tabular}{|c|c|c|c|c|c|c|c|c|c|c|}
\hline & \multicolumn{5}{|c|}{ Average $2000-2005$} & \multicolumn{5}{|c|}{ Pooled 2000-02 \& 2003-05 } \\
\hline & $(1)$ & $(2)$ & $(3)$ & $(4)$ & $(5)$ & $(6)$ & $(7)$ & $(8)$ & $(9)$ & $(10)$ \\
\hline & Em.Rate & Em.Rate & Em.Rate & Em.Rate & Em.Rate & Em.Rate & Em.Rate & Em.Rate & Em.Rate & Em.Rate \\
\hline \multirow[t]{2}{*}{ PMR } & $\begin{array}{c}-7.274 \\
* * *\end{array}$ & $\begin{array}{c}-6.747 \\
* * *\end{array}$ & $\begin{array}{c}-7.063 \\
* * *\end{array}$ & $\begin{array}{c}-7.398 \\
* * *\end{array}$ & $\begin{array}{c}-7.628 \\
* * *\end{array}$ & $\begin{array}{c}-8.953 \\
* * *\end{array}$ & $\begin{array}{c}-8.347 \\
* * *\end{array}$ & $\begin{array}{c}-8.677 \\
* * *\end{array}$ & $\begin{array}{c}-9.319 \\
* * *\end{array}$ & $\begin{array}{c}-9.349 \\
* * *\end{array}$ \\
\hline & $(2.012)$ & $(1.920)$ & $(1.917)$ & $(2.119)$ & $(2.078)$ & $(1.666)$ & $(1.630)$ & $(1.631)$ & $(1.699)$ & $(1.681)$ \\
\hline \multirow[t]{2}{*}{ Sum_LMP_1-9 } & $2.164 * *$ & & & & & $1.406 *$ & & & & \\
\hline & $(0.965)$ & & & & & $(0.696)$ & & & & \\
\hline \multirow[t]{2}{*}{ Sum_LMP_1-7 } & & $6.801^{* *}$ & & & & & $4.853 * *$ & & & \\
\hline & & $(2.423)$ & & & & & $(1.786)$ & & & \\
\hline \multirow[t]{2}{*}{ Sum_LMP_2-7 } & & & $6.709 * *$ & & & & & $4.598 * *$ & & \\
\hline & & & $(2.484)$ & & & & & $(1.869)$ & & \\
\hline \multirow[t]{2}{*}{ LMP_8 } & & & & $3.104 *$ & & & & & 1.787 & \\
\hline & & & & $(1.759)$ & & & & & $(1.237)$ & \\
\hline \multirow[t]{2}{*}{ Sum_LMP_8-9 } & & & & & $2.755^{*}$ & & & & & 1.617 \\
\hline & & & & & $(1.516)$ & & & & & $(1.059)$ \\
\hline Observations & 19 & 19 & 19 & 19 & 19 & 34 & 34 & 34 & 34 & 34 \\
\hline $\begin{array}{l}\text { Adjusted R- } \\
\text { squared }\end{array}$ & 0.54 & 0.60 & 0.59 & 0.49 & 0.50 & 0.56 & 0.60 & 0.58 & 0.53 & 0.54 \\
\hline
\end{tabular}


Table 5.2. Unemployment Rate; Explanatory Variables, Product Market Legislation and LMP

\begin{tabular}{|c|c|c|c|c|c|c|c|c|c|c|}
\hline & \multicolumn{5}{|c|}{ Average 2000-2005 } & \multicolumn{5}{|c|}{ Pooled 2000-02 \& 2003-05 } \\
\hline & $(1)$ & $(2)$ & (3) & $(4)$ & (5) & $(6)$ & $(7)$ & $(8)$ & (9) & $(10)$ \\
\hline & Un. Rate & Un. Rate & Un. Rate & Un. Rate & Un. Rate & Un. Rate & Un. Rate & Un. Rate & Un. Rate & Un. Rate \\
\hline \multirow[t]{2}{*}{ PMR } & $4.229 * *$ & $4.107 * *$ & $4.150 * *$ & $4.167^{* *}$ & $4.308^{* *}$ & $4.583 * * *$ & $4.422 * * *$ & $4.490 * * *$ & $4.573 * * *$ & $4.652 * * *$ \\
\hline & $(1.648)$ & $(1.668)$ & $(1.641)$ & $(1.648)$ & $(1.636)$ & $(1.099)$ & $(1.121)$ & $(1.103)$ & $(1.087)$ & $(1.080)$ \\
\hline \multirow[t]{2}{*}{ Sum_LMP_1-9 } & -0.460 & & & & & -0.084 & & & & \\
\hline & $(0.790)$ & & & & & $(0.459)$ & & & & \\
\hline \multirow[t]{2}{*}{ Sum_LMP_1-7 } & & -1.490 & & & & & -0.654 & & & \\
\hline & & $(2.105)$ & & & & & $(1.228)$ & & & \\
\hline \multirow[t]{2}{*}{ Sum_LMP_2-7 } & & & -1.608 & & & & & -0.539 & & \\
\hline & & & $(2.127)$ & & & & & $(1.265)$ & & \\
\hline \multirow[t]{2}{*}{ LMP_8 } & & & & -0.951 & & & & & -0.188 & \\
\hline & & & & $(1.368)$ & & & & & $(0.792)$ & \\
\hline \multirow[t]{2}{*}{ Sum_LMP_8-9 } & & & & & -0.571 & & & & & 0.014 \\
\hline & & & & & $(1.194)$ & & & & & $(0.681)$ \\
\hline Observations & 19 & 19 & 19 & 19 & 19 & 34 & 34 & 34 & 34 & 34 \\
\hline $\begin{array}{l}\text { Adjusted R- } \\
\text { squared }\end{array}$ & 0.25 & 0.26 & 0.26 & 0.26 & 0.25 & 0.37 & 0.37 & 0.37 & 0.37 & 0.37 \\
\hline
\end{tabular}


Table 5.3. Activity Rate; Explanatory Variables Product Market Legislation and LMP

\begin{tabular}{|c|c|c|c|c|c|c|c|c|c|c|}
\hline & \multicolumn{5}{|c|}{ Average $2000-2005$} & \multicolumn{5}{|c|}{ Pooled 2000-02 \& 2003-05 } \\
\hline & (1) & $(2)$ & $(3)$ & $(4)$ & $(5)$ & $(6)$ & $(7)$ & $(8)$ & $(9)$ & $(10)$ \\
\hline & Act. Rate & Act.Rate & Act.Rate & Act.Rate & Act.Rate & Act.Rate & Act. Rate & Act.Rate & Act.Rate & Act. Rate \\
\hline \multirow[t]{2}{*}{ PMR } & $\begin{array}{c}-4.765 \\
* *\end{array}$ & $\begin{array}{c}-4.306 \\
* *\end{array}$ & $\begin{array}{c}-4.609 \\
* *\end{array}$ & $\begin{array}{c}-4.921 \\
* *\end{array}$ & $\begin{array}{c}-5.082 \\
* *\end{array}$ & $\begin{array}{c}-6.223 \\
* * *\end{array}$ & $\begin{array}{c}-5.719 \\
* * *\end{array}$ & $\begin{array}{c}-6.020 \\
* * *\end{array}$ & $\begin{array}{c}-6.593 \\
* * *\end{array}$ & $\begin{array}{c}-6.590 \\
* * *\end{array}$ \\
\hline & $(1.840)$ & $(1.770)$ & $(1.778)$ & $(1.958)$ & $(1.896)$ & $(1.530)$ & $(1.510)$ & $(1.509)$ & $(1.572)$ & $(1.545)$ \\
\hline \multirow[t]{2}{*}{ Sum_LMP_1-9 } & $1.991^{* *}$ & & & & & $1.468 * *$ & & & & \\
\hline & $(0.882)$ & & & & & $(0.639)$ & & & & \\
\hline \multirow[t]{2}{*}{ Sum_LMP_1-7 } & & $6.148^{* *}$ & & & & & $4.691 * * *$ & & & \\
\hline & & $(2.234)$ & & & & & $(1.654)$ & & & \\
\hline \multirow[t]{2}{*}{ Sum_LMP_2-7 } & & & $5.975^{* *}$ & & & & & $4.506 * *$ & & \\
\hline & & & $(2.304)$ & & & & & $(1.729)$ & & \\
\hline \multirow[t]{2}{*}{ LMP_8 } & & & & 2.715 & & & & & 1.896 & \\
\hline & & & & $(1.625)$ & & & & & $(1.145)$ & \\
\hline \multirow[t]{2}{*}{ Sum_LMP_8-9 } & & & & & $2.569 *$ & & & & & $1.803^{*}$ \\
\hline & & & & & $(1.384)$ & & & & & $(0.974)$ \\
\hline Observations & 19 & 19 & 19 & 19 & 19 & 34 & 34 & 34 & 34 & 34 \\
\hline $\begin{array}{l}\text { Adjusted R- } \\
\text { squared }\end{array}$ & 0.43 & 0.49 & 0.47 & 0.36 & 0.38 & 0.46 & 0.50 & 0.48 & 0.42 & 0.43 \\
\hline
\end{tabular}


Table 6.1. Employment Rate; Explanatory Variables Tax Wedge and LMP

\begin{tabular}{|c|c|c|c|c|c|c|c|c|c|c|}
\hline & \multicolumn{5}{|c|}{ Average 2000-2005 } & \multicolumn{5}{|c|}{ Pooled 2000-02 \& 2003-05 } \\
\hline & (1) & $(2)$ & $(3)$ & $(4)$ & $(5)$ & $(6)$ & $(7)$ & $(8)$ & (9) & $(10)$ \\
\hline & Em.Rate & Em.Rate & Em.Rate & Em.Rate & Em.Rate & Em.Rate & Em.Rate & Em.Rate & Em.Rate & Em.Rate \\
\hline \multirow[t]{2}{*}{ Tax_Wedge } & $-0.292 *$ & -0.268 & -0.255 & $-0.296 *$ & -0.285 & $-0.261 * *$ & $-0.250 * *$ & $-0.239 *$ & $-0.243 *$ & $-0.238^{*}$ \\
\hline & $(0.166)$ & $(0.159)$ & $(0.164)$ & $(0.171)$ & $(0.174)$ & $(0.125)$ & $(0.116)$ & $(0.121)$ & $(0.131)$ & $(0.132)$ \\
\hline \multirow[t]{2}{*}{ Sum_LMP_1-9 } & $3.643 * * *$ & & & & & $3.261 * * *$ & & & & \\
\hline & $(1.011)$ & & & & & $(0.810)$ & & & & \\
\hline \multirow[t]{2}{*}{ Sum_LMP_1-7 } & & $9.962 * * *$ & & & & & $9.260 * * *$ & & & \\
\hline & & $(2.594)$ & & & & & $(1.986)$ & & & \\
\hline \multirow[t]{2}{*}{ Sum_LMP_2-7 } & & & $9.804 * * *$ & & & & & $9.105^{* * *}$ & & \\
\hline & & & $(2.769)$ & & & & & $(2.199)$ & & \\
\hline \multirow[t]{2}{*}{ LMP_8 } & & & & $\begin{array}{l}6.169 \\
* * *\end{array}$ & & & & & $\begin{array}{l}5.048 \\
* * *\end{array}$ & \\
\hline & & & & $(1.825)$ & & & & & $(1.492)$ & \\
\hline \multirow[t]{2}{*}{ Sum_LMP_8-9 } & & & & & $\begin{array}{l}5.113 \\
* * *\end{array}$ & & & & & $\begin{array}{l}4.313 \\
* * *\end{array}$ \\
\hline & & & & & $(1.609)$ & & & & & $(1.296)$ \\
\hline Observations & 24 & 24 & 24 & 24 & 24 & 40 & 40 & 40 & 40 & 40 \\
\hline $\begin{array}{l}\text { Adjusted R- } \\
\text { squared }\end{array}$ & 0.33 & 0.37 & 0.32 & 0.30 & 0.27 & 0.28 & 0.35 & 0.29 & 0.21 & 0.20 \\
\hline
\end{tabular}


Table 6.2. Unemployment Rate; Explanatory Variables Tax Wedge and LMP

\begin{tabular}{|c|c|c|c|c|c|c|c|c|c|c|}
\hline & \multicolumn{5}{|c|}{ Average 2000-2005 } & \multicolumn{5}{|c|}{ Pooled 2000-02 \& 2003-05 } \\
\hline & (1) & $(2)$ & $(3)$ & $(4)$ & (5) & $(6)$ & $(7)$ & $(8)$ & $(9)$ & $(10)$ \\
\hline & Un. Rate & Un. Rate & Un.Rate & Un. Rate & Un. Rate & Un. Rate & Un. Rate & Un. Rate & Un. Rate & Un.Rate \\
\hline \multirow[t]{2}{*}{ Tax_Wedge } & 0.202 & 0.184 & 0.180 & $0.217 *$ & 0.203 & $0.174 * *$ & $0.169 * *$ & $0.164 * *$ & $0.176 * *$ & $0.168^{* *}$ \\
\hline & $(0.121)$ & $(0.121)$ & $(0.121)$ & $(0.118)$ & $(0.123)$ & $(0.074)$ & $(0.072)$ & $(0.073)$ & $(0.074)$ & $(0.075)$ \\
\hline \multirow[t]{2}{*}{ Sum_LMP_1-9 } & $-1.680 * *$ & & & & & $-1.052 * *$ & & & & \\
\hline & $(0.740)$ & & & & & $(0.480)$ & & & & \\
\hline \multirow[t]{2}{*}{ Sum_LMP_1-7 } & & $-4.219 * *$ & & & & & $-2.913 * *$ & & & \\
\hline & & $(1.968)$ & & & & & $(1.224)$ & & & \\
\hline \multirow[t]{2}{*}{ Sum_LMP_2-7 } & & & $-4.215^{*}$ & & & & & $-2.760 * *$ & & \\
\hline & & & $(2.050)$ & & & & & $(1.321)$ & & \\
\hline \multirow[t]{2}{*}{ LMP_8 } & & & & $-3.292 * *$ & & & & & $-1.853 * *$ & \\
\hline & & & & $(1.266)$ & & & & & $(0.842)$ & \\
\hline \multirow[t]{2}{*}{ Sum_LMP_8-9 } & & & & & $-2.483 * *$ & & & & & $-1.416 *$ \\
\hline & & & & & $(1.134)$ & & & & & $(0.739)$ \\
\hline Observations & 24 & 24 & 24 & 24 & 24 & 40 & 40 & 40 & 40 & 40 \\
\hline $\begin{array}{l}\text { Adjusted R- } \\
\text { squared }\end{array}$ & 0.15 & 0.14 & 0.12 & 0.20 & 0.14 & 0.18 & 0.20 & 0.17 & 0.18 & 0.16 \\
\hline
\end{tabular}


Table 6.3. Activity Rate; Explanatory Variables, Tax Wedge and LMP

\begin{tabular}{|c|c|c|c|c|c|c|c|c|c|c|}
\hline & \multicolumn{5}{|c|}{ Average $2000-2005$} & \multicolumn{5}{|c|}{ Pooled 2000-02 \& 2003-05 } \\
\hline & $(1)$ & $(2)$ & $(3)$ & $(4)$ & (5) & (6) & $(7)$ & (8) & $(9)$ & $(10)$ \\
\hline & Act. Rate & Act. Rate & Act. Rate & Act.Rate & Act. Rate & Act.Rate & Act. Rate & Act. Rate & Act. Rate & Act. Rate \\
\hline \multirow[t]{2}{*}{ Tax_Wedge } & -0.161 & -0.146 & -0.136 & -0.156 & -0.153 & -0.150 & -0.140 & -0.132 & -0.131 & -0.131 \\
\hline & $(0.141)$ & $(0.135)$ & $(0.138)$ & $(0.148)$ & $(0.147)$ & $(0.108)$ & $(0.101)$ & $(0.104)$ & $(0.114)$ & $(0.113)$ \\
\hline \multirow[t]{2}{*}{ Sum_LMP_1-9 } & $2.652 * * *$ & & & & & $2.728 * * *$ & & & & \\
\hline & $(0.861)$ & & & & & $(0.699)$ & & & & \\
\hline \multirow[t]{2}{*}{ Sum_LMP_1-7 } & & $7.452 * * *$ & & & & & $7.711 * * *$ & & & \\
\hline & & $(2.193)$ & & & & & $(1.724)$ & & & \\
\hline \multirow[t]{2}{*}{ Sum_LMP_2-7 } & & & $7.291 * * *$ & & & & & $7.657 * * *$ & & \\
\hline & & & $(2.333)$ & & & & & $(1.894)$ & & \\
\hline \multirow[t]{2}{*}{ LMP_8 } & & & & $4.233 * *$ & & & & & $4.137 * * *$ & \\
\hline & & & & $(1.579)$ & & & & & $(1.292)$ & \\
\hline \multirow[t]{2}{*}{ Sum_LMP_8-9 } & & & & & $3.654 * *$ & & & & & $3.620 * * *$ \\
\hline & & & & & $(1.364)$ & & & & & $(1.114)$ \\
\hline Observations & 24 & 24 & 24 & 24 & 24 & 40 & 40 & 40 & 40 & 40 \\
\hline $\begin{array}{l}\text { Adjusted R- } \\
\text { squared }\end{array}$ & 0.25 & 0.29 & 0.25 & 0.19 & 0.19 & 0.24 & 0.31 & 0.26 & 0.16 & 0.17 \\
\hline
\end{tabular}


Table 7. Employment rate - Comparison of Eurostat and OECD measures of labor and social policies.

\begin{tabular}{|c|c|c|c|c|c|c|c|}
\hline & $\begin{array}{l}\text { Pooled 2000-02 } \\
\quad \& 2003-05\end{array}$ & \multicolumn{6}{|c|}{ Pooled 1998-2000 \& 2000-03 } \\
\hline & $(1 a)$ & (1b) & $(2)$ & $(3)$ & $(4)$ & $(5)$ & $(6)$ \\
\hline & \multicolumn{2}{|c|}{$\begin{array}{c}\text { Eurostat: } \\
\text { ALMP (Sum_LMP_1-7) }\end{array}$} & $\begin{array}{l}\text { OECD: } \\
\text { ALMP }\end{array}$ & $\begin{array}{l}\text { OECD: } \\
\text { UB }\end{array}$ & $\begin{array}{c}\text { OECD: } \\
\text { ALMP+UB }\end{array}$ & $\begin{array}{c}\text { OECD: } \\
\text { ALMP+UB } \\
\text { +Family } \\
\text { +Housing }\end{array}$ & $\begin{array}{l}\text { OECD: } \\
\text { All Social } \\
\text { Policies }\end{array}$ \\
\hline & $\begin{array}{c}\text { from Tab } 3.1 \\
\text { eq.(7) }\end{array}$ & & & & & & \\
\hline \multirow[t]{2}{*}{ Rig_Emp } & $-0.149 * *$ & $-0.184 * * *$ & $-0.193 * * *$ & $-0.190 * *$ & $-0.188 * *$ & $-0.126 *$ & $-0.215^{* * *}$ \\
\hline & $(0.058)$ & $(0.057)$ & $(0.062)$ & $(0.073)$ & $(0.070)$ & $(0.071)$ & $(0.073)$ \\
\hline \multirow[t]{2}{*}{ Policy Measure } & $7.008 * * *$ & $5.633 * * *$ & $8.193 * * *$ & 2.025 & $2.056 * *$ & $1.601 * * *$ & $0.493 *$ \\
\hline & $(1.979)$ & $(1.911)$ & $(1.925)$ & $(1.231)$ & $(0.800)$ & $(0.523)$ & $(0.271)$ \\
\hline Observations & 38 & 34 & 36 & 36 & 36 & 36 & 36 \\
\hline $\begin{array}{l}\text { Adjusted R- } \\
\text { squared }\end{array}$ & 0.39 & 0.41 & 0.43 & 0.19 & 0.27 & 0.32 & 0.20 \\
\hline
\end{tabular}

